\title{
Comparison of Tritiated-Water Standards by Liquid Scintillation for Calibration of a New Standard Reference Material
}

\author{
R Collé, L Laureano-Perez and D E Bergeron \\ National Institute of Standards and Technology \\ Gaithersburg, MD 20899-8462 USA \\ E-mail: rcolle@ nist.gov
}

\begin{abstract}
A new National Institute of Standards and Technology (NIST) tritiated-water $\left({ }^{3} \mathrm{H}\right.$-labeled oxidane) standard was prepared and calibrated. It is the $17^{\text {th }}$ in a series of linked standards since 1954 and will be disseminated as Standard Reference Material ${ }^{\circledR}$ SRM 4927G, having a massic activity of $544.2 \mathrm{kBq} \mathrm{g}^{-1}$, with an expanded $(k=2)$ relative standard uncertainty of $0.96 \%$, at a Reference Time of 1200 EST, 1 May 2015. The calibration is based on relative liquid scintillation (LS) measurements using quenchvaried efficiency tracing with two previous 1999 issues, viz., SRM 4927F and 4926E. Measurement comparisons were also made with respect to a 1994 tritiated-water French national standard and to a tritiated-water solution measured by 19 laboratories as part of an international measurement comparison organized by the Bureau International des Poids et Mesures (BIPM) in 2009. Confirmatory measurements for the massic activity of both SRM 4927F and 4927G by a triple-to-double coincidence ratio (TDCR) technique were also made.
\end{abstract}

Key words: hydrogen-3; liquid scintillation (LS); NIST; standard; Standard Reference Material (SRM); triple-to-double coincidence ratio (TDCR); tritium 


\section{Historical overview}

Standards of the radionuclide ${ }^{3} \mathrm{H}$ (tritium), often in the form of tritiated water ${ }^{1}$ solutions, play a vital role in metrology. Measurement comparisons of tritium solutions amongst metrology laboratories serve as a stringent test of measurement capability for nuclides that decay by very low energy, pure beta decay. Tritium standards are used to evaluate and monitor commercial liquid scintillation (LS) counter performance. For the standardization of other radionuclides, they are used as efficiency tracing monitors in the LS-based CIEMAT/NIST ${ }^{2}$ measurement method. In addition, nuclear power and environmental radiation measurement communities rely on ${ }^{3} \mathrm{H}$ standards for calibrations and quality control in surveillance programs.

Lucas [1] previously summarized the sixteen different tritiated-water standards disseminated by the National Institute of Standards and Technology (NIST), formerly the National Bureau of Standards (NBS), from 1954 to 1999. The most recent of these were standardized by length-compensated internal gas proportional counting [2-4]. ${ }^{3}$ The procedure for the preparation of tritiated-water standards and the internal proportional gas counting method used at NIST has been described by Unterweger et al. [7] and Unterweger and Lucas [8].

An international comparison of tritiated water measurements by gas counting between NIST, the National Physical Laboratory (NPL) of the U.K. and the Physikalisch-Technische Bundesanstalt (PTB) of Germany was conducted in 1995. Stated uncertainties (consistent with " $1 \sigma$ ") were in the range of $0.4 \%$ to $1 \%$. The comparison demonstrated agreement amongst the laboratories consistent with " $3 \sigma$ " uncertainties (PTB and NIST agreed at " $1 \sigma$ ", while the NPL activity was significantly high) as used at the time [9]. A larger international comparison amongst nine national metrology laboratories, reported on in 1998 [10], demonstrated agreement only on the order of $\pm 5 \%$ (as a range), with stated uncertainties that

\footnotetext{
${ }^{1}$ Tritiated water refers to $\mathrm{H}_{2} \mathrm{O}$, oxidane, isotopically labeled with ${ }^{3} \mathrm{H}$, as a solution of ${ }^{1} \mathrm{H}_{2} \mathrm{O}$ and ${ }^{3} \mathrm{H}^{1} \mathrm{HO}$.

${ }^{2}$ CIEMAT/NIST is an acronym that refers to the two laboratories that collaborated in developing the protocol for a ${ }^{3} \mathrm{H}$-standard efficiency tracing methodology; viz., the Centro De Investigaciones Energéticas Medioambientales y Tecnológicas (CIEMAT) and the National Institute of Standards and Technology (NIST), which are the national metrological standards laboratories of Spain and the USA, respectively.

${ }^{3}$ It may be of historical interest to note that the first NBS/NIST ${ }^{3} \mathrm{H}$ standard, and perhaps the earliest standard of this radionuclide from any laboratory, was calibrated in 1954 by microcalorimetry with $0.2 \mathrm{TBq}(4.8 \mathrm{Ci})$ of tritiated water $[5,6]$. The standard was reissued in 1961 after recalibration by gas counting.
} 
did not cover the dispersion in the results. Measurements for the comparison were performed by a variety of methods, principally internal gas proportional counting and liquid scintillation.

In addition, Zimmerman and Collé [11] in 1996 made a direct comparison between the then extant French and U.S. national standards for tritiated-water that were used as efficiency tracing monitors in liquid scintillation. The French standard from Laboratoire Primaire des Rayonnements Ionisants (LPRI), now known as Laboratoire National Henri Becquerel (LNHB), was certified with a reference date of 27 January 1994 [12]; whereas the US standard was a Standard Reference Material (SRM) ${ }^{4}, 4927 \mathrm{E}$, certified with reference date of 15 August 1995 [13]. The ratio of the massic activities for the two standards relative to the ratio of their certified values, as obtained from seven experimental trials of comparative LS measurements with quench matching under a wide variety of counting conditions, was $0.9963 \pm 0.0014$, where the cited uncertainty is the standard deviation of the mean on the ratio. Given that the relative combined standard uncertainty on the ratio of the certified massic activities for the two standards was about $0.7 \%$, the two standards were found to be in good agreement within their respective certified uncertainty assessments.

More recently, an international comparison of activity measurements of a tritiated-water solution was organized by the Bureau International des Poids et Mesures (BIPM) in 2009 under the aegis of the Comite Consultatif des Rayonnements Ionisants CCRI(II). The tritiated water solution used for the comparison was prepared and distributed by the LNHB laboratory, and 22 independent results from 19 laboratories were reported [14]. The consensus central value for the comparison, in terms of a Key Comparison Reference Value (KCRV), had a $k=1$ relative uncertainty of $0.48 \%$. The absence of an operable gas counting system at NIST at the time weighed heavily, along with other factors, in the NIST decision not to participate in the comparison.

This paper reports on the preparation of a new standard ${ }^{5}$, SRM 4927G, and its calibration by comparison against two previous 1998 NIST SRMs (viz., SRM 4927F and 4926E), as well as to the 1994 LPRI standard (F1994) that was measured previously by Zimmerman and Collé [11] in 1996, and with

\footnotetext{
${ }^{4}$ Standard Reference Material ${ }^{\circledR}$ (SRM), trademarked and disseminated by NIST, is a certified reference material that is issued with a certificate that provides the value of the specified property, its associated uncertainty, and a statement of metrological traceability.

${ }^{5}$ Upper case letters as suffixes are used as designators to identify subsequent issues of an SRM, such as 4927F for the $7^{\text {th }}$ issue of SRM 4927. The NIST now requires that subsequent issues be designated by lower case suffixes, as in SRM 4927g. Both 4927F and 4926E were designated as such in original certification documentation. Therefore, we have for consistency and only for purposes of this paper used an upper case letter suffix for the new standard.
} 
comparisons to the 2009 solution distributed by LNHB (F2009) for the international comparison. These comparison measurements were made by relative LS counting with quench-varied efficiency tracing.

\section{Experimental aspects}

\subsection{Preparation of SRM 4927G}

The overall scheme used for the preparation and calibration of SRM 4927G is illustrated in Figure 1. A stock solution of "biological grade" tritiated water was obtained from American Radiolabeled Chemicals Inc. (St. Louis, MO, USA) ${ }^{6}$ in August 2009. The present work was initiated in April 2015. The stock solution consisted of a nominal $3.7 \mathrm{GBq}$ (i.e., $100 \mathrm{mCi}$ ) ${ }^{3} \mathrm{H}$ in a volume of about $1.4 \mathrm{~mL}$ and was contained in a $5 \mathrm{~mL}$, glass, vee-vial. The stock solution was transferred with an aspirating polyethylene pycnometer with water rinses and diluted to approximately $25 \mathrm{~mL}$. The resulting solution of about $100 \mathrm{MBq} \mathrm{g}^{-1}$ (with decay correction to 2015) was dispensed and contained in five flame-sealed 5 $\mathrm{mL}$ glass ampoules, labeled M1 through M5. Ampoule M3 was subsequently used to prepare the SRM dispensing solution. The other four master ampoules will be stored for use in preparing subsequent ${ }^{3} \mathrm{H}$ SRM solutions in later years.

An SRM dispensing solution was prepared by diluting the entire contents of ampoule M3 to about $875 \mathrm{~g}$ with deionized, distilled water. A gravimetric dilution factor of $175.921 \pm 0.035$ was determined ${ }^{7}$. The procedure used to perform such large-volume gravimetric dilutions has been described in detail previously by Collé, et al. [17] for the preparation of a different radioactivity SRM. For this dilution, the mass from ampoule M3 was obtained from both dispensed and contained mass differences with a Mettler AT20 electronic microbalance (Mettler-Toledo, Columbus, Ohio) and a larger-capacity (3 $\mathrm{kg}$ ) mechanical balance with optical scale (Voland Jupiter 3000$)^{8}$, respectively. The total mass was obtained from the mass difference between the empty dispensing bottle and the filled bottle with the large capacity balance. Both balances were checked for possible calibration errors at the time of the measurements with

\footnotetext{
${ }^{6}$ Certain commercial equipment, instruments, or materials are identified in this paper to foster understanding. Such identification does not imply recommendation by the National Institute of Standards and Technology, nor does it imply that the materials or equipment identified are necessarily the best available for the purpose.

${ }^{7}$ The stated uncertainty is two times the standard uncertainty. Unless otherwise noted all uncertainties given in this paper correspond to standard uncertainties multiplied by a coverage factor of $k=2$. The treatment and reporting of uncertainties follows NIST policy and the international conventions given in Taylor and Kuyatt [15] and JCGM [16].

${ }^{8}$ Voland \& Sons, Inc., formerly of New Rochelle, New York.
} 
OIML Class E1 standard weights ${ }^{9}$ in the exact mass ranges used for the mass difference determinations (single substitution with sensitivity weights), including for the dispensed mass of master solution and the contained mass of the master solution and total contained mass.

The resulting SRM 4927G solution was dispensed into approximately 175 borosilicate glass ampoules using a Microlab 620 single-syringe automatic dispenser (Hamilton Company, Reno, Nevada). Ten ampoules, roughly every twentieth one that was filled, had been pre-weighed and then post-weighed to obtain an estimate of the dispensing precision and contained solution mass. Weighing was performed with an electronic analytical balance (Mettler AE240). The average mass was $4.992 \mathrm{~g}$ with a relative standard deviation of $0.02 \%$ for the $n=10$ sample distribution, which included one outlier at $-0.07 \%$ away from the mean. After filling and weighing, the ampoules were flame sealed, inspected, autoclaved, and labelled.

\subsection{Tritiated-water solutions}

The properties of the four tritiated-water solutions used in comparison with SRM 4927G are summarized in Table 1. To achieve practicable counting rates for sources prepared with reasonably sized aliquants, solutions of both SRM 4927F and the newly prepared SRM 4927G required dilutions to reduce the massic activity levels. Three ampoules of SRM 4927G (\#47,\#113, and \#172) were randomly selected for sampling. The gravimetric dilutions were performed with aspirating pycnometers, and both contained and dispensed mass differences for both the diluent water and ${ }^{3} \mathrm{H}$ solution aliquants were obtained with a Mettler AT20 electronic microbalance. Table 2 provides the dilution factors $D$, given by the contained mass of the total dilution (nominally $5 \mathrm{~g}$ ) divided by the dispensed mass of the ${ }^{3} \mathrm{H}$ solution aliquant, as well as the measurement agreement between the contained and dispensed masses.

The two French solutions (F1994 and F2009) were obtained by NIST as sources distributed for international comparisons in 1994 and 2009, respectively. The solutions from their initial receipt in the NIST laboratory, even after opening for sampling and transferring the contents, were stored in flamesealed glass ampoules.

\subsection{LS counting sources}

\footnotetext{
${ }^{9}$ Organisation Internationale de Métrologie Légale (OIML), which defines the requirements for various classes of weights, classifies E1 as mass standards, one level below E0 national primary mass standards.
} 
Seven different series of LS counting sources were prepared for the comparisons. Within each series the sources were closely matched for composition. The cocktail compositions of these are given in Table 3. In each trial, sets of 5 or 6 sources were prepared for each of a selection of the five master solutions (SRM 4927G and the four given in Table 1). The cocktails were gravimetrically prepared with aliquants of the ${ }^{3} \mathrm{H}$ solutions as dispensed by a polyethylene aspirating pycnometer and measured with an electronic microbalance (Mettler AT20). Other cocktail components were weighed with a mechanical analytical balance (Mettler B5). Within a set, the sources were closely matched in terms of size of the ${ }^{3} \mathrm{H}$ aliquant, the aqueous fraction, and total volume. To vary the detection efficiencies within a set, variable quantities of a $5 \mathrm{mmol} \mathrm{g}^{-1}$ ethanolic solution of nitromethane were added to impose quenching. Three blank sources (for subsequent background subtraction) of similar composition over the same quench range were also prepared for each series. The first three series were prepared with UltimaGold $A B$ (UGAB) scintillation fluid (PerkinElmer, Waltham, MA) and an aqueous mass fraction $f_{\text {aq }}$ of about $6 \%$ to $7 \%$ in $20 \mathrm{~mL}$ glass LS vials. Series IV through VII were prepared with UltimaGold (UG) in $20 \mathrm{~mL}$ plastic (high-density polyethylene) LS vials. A cocktail composition with an aqueous fraction of about 2 $\%$ to $3 \%$ was used for series IV and V. This was chosen on the basis of the systematics of micelle formation in which no critical micelle concentration or phase boundary had been observed at low $f_{\text {aq }}$ in UG [21]. Unfortunately, these cocktails were subsequently found to be temporally unstable to the extent of exhibiting ${ }^{3} \mathrm{H}$ efficiency decreases on the order of $2 \%$ to $4 \%$ per day. The last two series (VI and VII) had compositions similar to Series IV and V excepting that $f_{\text {aq }}$ was increased to about $7 \%$. The sources for Series V and VII with a more limited range of quench variation and fewer sources were used exclusively for confirmatory measurements by LS-based triple-to-double-coincidence-ratio (TDCR) counting (see Annex B).

\subsection{Measurement conditions and protocol}

In all, 14 measurement trials were conducted using sources from the various series. Figure 2 in tabular form shows the counting scheme for these trials. Each set of sources for a given trial was measured on either one of two different LS counters; viz.,

Beckman LS 6500 (Beckman Coulter, Fullerton, CA), designated as counter "B"; and

Wallac 1414 Winspectral (PerkinElmer, Wesley, MA), designated as counter "W"

More than one LS counter is typically used in our laboratory for any given set of calibration experiments to hopefully demonstrate that results are independent of the operating characteristics of a particular instrument (detection threshold, photomultiplier efficiency, deadtime, amplification, signal conversion, 
etc.). The characteristics of these counters vary substantially and their differences have been described by Laureano-Perez et al. [22].

For each trial, the sources were measured five times in five measurement cycles with the sources intermixed and ordered by quench level. For example, in Trial 1 (Fig. 2), the least quenched source for SRM 4927F was followed by the counting of the least quenched sources for SRM 4927G, and F2009, which was then followed by the same sequence of sources at the next quench level, and onwards to the highest quench level. Each source for a given measurement was counted for a 1200 second interval. Typical counting rates for the sources ranged from about $500 \mathrm{~s}^{-1}$ to $1200 \mathrm{~s}^{-1}$, with a relative Poisson statistical counting error of $<0.13 \%$ for any single measurement.

For each measurement the integral counting rate $R$ for the source in a pre-set tritium window was measured as a function of a time-of-measurement stamp and determination of a quench indicating parameter $Q$, as obtained with an external gamma radiation source to create a Compton spectrum in the cocktail. The Beckman counter B uses a Horrocks Number $H \#$ to monitor the quench level, which is based on the downward spectrum shift of the Compton edge of an external ${ }^{137} \mathrm{Cs}$ source with increasing quenching in the cocktail; while the Wallac counter W uses a proprietary mathematical transform called the "Spectral Quench Parameter of External Standard" (SQPE) [23], which is related to the endpoint of the Compton spectrum of ${ }^{152} \mathrm{Eu}$.

The Beckman counter B collects spectral data in a linear energy scale (of roughly $1 \mathrm{keV}$ per channel), and the ${ }^{3} \mathrm{H}$ window for the upper discriminator level was conservatively set for all measurements at channel 50. The Wallac counter W uses a logarithmic scale, and the ${ }^{3} \mathrm{H}$ window was set for all measurements at channel 400. One should appreciate that in a log spectrum mode the difference in any two channels $\left(c_{2}-c_{1}\right)$ or the energy bin width of a single channel is equal to the logarithmic energy ratio $\log \left(E_{2} / E_{1}\right)$. The background-subtracted rates in each channel above the ${ }^{3} \mathrm{H}$ windows were essentially zero in all cases, as quantified in Annex A.

The quench-varied efficiency ranges for the source sets in all the trials were about $27 \%$ to $48 \%$ for counter B and about $20 \%$ to $39 \%$ for counter W. Figures 3 and 4 show typical spectra obtained with sources at two quench levels in both counters. 
The comparison measurements were conducted by efficiency tracing each of the other solutions against the dilution of SRM 4927F. Each measurement of a SRM 4927F counting source was used to derive a quench-dependent ${ }^{3} \mathrm{H}$ efficiency $\varepsilon_{3}(Q)$ as given by

$$
\varepsilon_{3}(Q)=\frac{\left(R-R_{\mathrm{b}}\right)}{m D\left[\exp \left(-\lambda t_{m}\right)\right] A_{s}\left[\exp \left(-\lambda t_{s}\right)\right]}
$$

where

$Q \quad$ is the quench indicating paramete $r$ for the measurement, with $Q=H \#$ for counter B and $Q=S P Q E$ for counter $\mathrm{W}$;

$R_{\mathrm{b}} \quad$ is a background counting rate obtained from a blank source of comparable quenching to that used to obtain the source counting rate $R$;

$m \quad$ is the aliquot mass of the diluted SRM 4927F solution used to prepare the counting source;

$D \quad$ is the dilution factor for the SRM 4927F solution (Table 2);

$\lambda \quad$ is the ${ }^{3} \mathrm{H}$ decay constant given by $\ln (2) / T$ for ${ }^{3} \mathrm{H}$ half-life of $T=(12.312 \pm 0.025)$ a [23];

$t_{\mathrm{m}} \quad$ is the time interval from the measurement midpoint time $t$ for the source (as determined from the time stamp) to the standardization Reference Time $t_{\mathrm{G}}$ for SRM 4927G, as well as that for the other solution comparisons, which is 1200 EST, 1 May 2015 (Julian Day Number 121.5), given by $t_{\mathrm{m}}=\left(t_{\mathrm{G}}-t\right)$;

$A_{\mathrm{s}} \quad$ is the certified massic activity for SRM 4927F at its Reference Time (Table 1);

$t_{\mathrm{S}} \quad$ is the time interval from the Reference Time for SRM 4927F, $t_{\mathrm{F}}$, to the Reference Time for SRM $4927 \mathrm{G}, t_{\mathrm{G}}$, given by $t_{\mathrm{s}}=\left(t_{\mathrm{G}}-t_{\mathrm{F}}\right)$.

For each trial, the data for all 30 determinations of $\varepsilon_{3}(Q)$ for SRM 4927F and its corresponding $Q$ value (for 5 measurements on each of 6 sources) were fit to a second-order polynomial. The resulting $\varepsilon_{3}(Q)$ vs. $Q$ quench function, given by

$$
F(Q)=a Q^{2}+b Q+c
$$

(with polynomial fit parameters $a, b$, and $c$ ) was then used to trace the efficiency for all other sources in the trial. The ${ }^{3} \mathrm{H}$ massic activity $A$ for a given source measurement in a specific trial was then derived 
from its respective $R, Q$, and $t_{\mathrm{m}}$ counting data on applying the usual background and decay corrections along with the solution's aliquot mass $m$ and dilution factor $D$ :

$$
A=\frac{\left(R-R_{\mathrm{b}}\right)}{m D\left[\exp \left(-\lambda t_{m}\right)\right] F(Q)}
$$

Analyses of the efficiency-traced massic activities for each solution in a given trial were performed as follows. The 5 determinations of the massic activity $A$ for each source in a trial was averaged and the within-source standard deviation of the mean $s_{\mathrm{m}}$ was calculated. The mean values for the 5 or 6 sources for a given solution (Table 3) was in turn averaged to form a grand mean $\bar{A}$. The full standard deviation $s_{\mathrm{B}}$ on this grand mean $\bar{A}$ for the $n=5$ or $n=6$ source means gives the between-source variation. The typical within-source variation $s_{\mathrm{W}}$ is taken to be the average of the mean and median of the $n=5$ or $n=6 s_{\mathrm{m}}$ values. The equivalent standard deviation on grand mean $\bar{A}$ for a given solution for a specific trial (Fig. 2) is then given by $s_{\mathrm{T}}=\left(s_{\mathrm{W}}{ }^{2}+s_{\mathrm{B}}{ }^{2}\right)^{1 / 2}$, which accounts for both the within-source (i.e., between-measurement) and between source variability. Hence, the comparison evaluation of one of the other solutions with respect to the massic activity of SRM 4927F can be characterized by $\bar{A}$ and $s_{\mathrm{T}}$ as determined for that solution in the trial. The approach used here yields a very conservative estimate of the imprecision in the measured massic activity, but is believed to be an appropriate representation of the true experimental variance for replicate measurements with multiple sources.

\section{Results of the comparisons and discussion}

Figures 5 and 6 provide representative examples of typical quench curves developed from the $\varepsilon_{3}(Q)$ efficiencies for SRM 4927F. The quench functions $F(Q)$ for each of the 14 trials were used to trace the efficiencies and compare the massic activities for the other four ${ }^{3} \mathrm{H}$ solutions. The standard deviation on the relative residuals for each of the 14 fits ranged from $0.16 \%$ to $0.49 \%$, with mean and median values of $0.31 \%$ and $0.28 \%$, respectively. There were no apparent trends in the residuals. The reduced value (by $\sqrt{ } 14$ ) for a fitting uncertainty component is therefore estimated at $0.08 \%$

\subsection{SRM 4927G}

The results for the 14 measurement trials for the calibration of SRM 4927G are given in Table 4. As noted in Sect 2.4, each grand mean $\bar{A}$ for a given trial was obtained from averaging the mean from $n$ quench-varied sources, where each source was measured 5 times. The measurement precision estimator $s_{\mathrm{T}}$ 
on each $\bar{A}$ value was obtained from the quadratic addition of the between-source and within-source variations, $s_{\mathrm{B}}$ and $s_{\mathrm{W}}$, respectively. The $14 \bar{A}$ values were averaged to obtain the great-grand mean $\overline{\bar{A}}$. The between-trial variation $S_{\mathrm{B}}$ is the relative standard deviation for the $\bar{A}$ variate. The typical within-trial variation $S_{\mathrm{W}}$ was taken to be the average of the mean and median of the 14 values of $\left(s_{\mathrm{T}} / \sqrt{ } n\right)$. The overall precision estimator $S$, representing the equivalent relative standard deviation on the great-grand mean $\overline{\bar{A}}$, is the propagation of $S_{\mathrm{B}}$ and $S_{\mathrm{W}}$ in quadrature. This is a conservative, but realistic, estimate of the LS measurement precision for the $\overline{\bar{A}}$ determination.

The Fitzgerald plot, shown in Figure 7, demonstrates the normality of the data based on a probability plot correlation coefficient (PPCC) [25]. The data pass both an Anderson-Darling goodness of fit test $(p \approx 0.503)$ and a Wilk-Shapiro test for normality $(p \approx 0.516)$ [26].

The cocktail instabilities in the counting sources for Trials 11 and 12 with Series IV sources, as noted in Section 2.3, yield results that exhibit a curious effect. As indicated in Table 4, the grand mean values of $\bar{A}$ for both trials converge and agree with the apparent central value for $\overline{\bar{A}}$, yet the large imprecision in the within-source measurement variation $s_{\mathrm{W}}$ is clearly evident. A typical value of $s_{\mathrm{W}}$ for the other 10 trials is about $0.25 \%$, while those for these two trials with temporally unstable sources range from $1.3 \%$ to $1.5 \%$. This is also nicely seen by the horizontal uncertainty bars in Figure 7.

Closer examination of the data is even more revealing. If all $390 \mathrm{~A}$ values comprised in $\overline{\bar{A}}$, are collectively ungrouped ("thrown into the same pot"), then the relative standard deviation of the mean would be $0.03 \%$, which would grossly underestimate the realistic measurement variation on $\overline{\bar{A}}$. Evaluation of all 390 values, at the same time, clearly demonstrates that the data would fail normality tests at virtually all confidence levels. This is a clear validation of the need to evaluate uncertainties by considering within and between components of variance.

The $\bar{A}$ data were examined for possible differences between counters (B vs. W) and cocktail compositions (UGAB in glass vs. UG in plastic) using $t$ - and $F$-tests. The individual means for the two counters are $(544.20 \pm 0.35) \mathrm{kBq} \mathrm{g}^{-1}$ and $(544.19 \pm 0.52) \mathrm{kBq} \mathrm{g}^{-1}$ for the Beckman and Wallac counters, respectively, where the cited uncertainties are the standard deviations of the mean with $n=7$. Considering that the two means differ by $<0.002 \%$, a formal $t$-test is hardly necessary. The ratio of the two variances gives $F=2.16$, with $p=0.18$, indicating no significant difference between the variation with the Beckman counter data compared to that obtained with the Wallac W. The critical values of $F$ for significance levels of $\alpha=0.01$ and $\alpha=0.05$ with equal degrees of freedom of $v=6$ are $F=8.47$ and $F=4.28$, respectively. 
Similarly, the means for the two source compositions are $(543.96 \pm 0.41) \mathrm{kBq} \mathrm{g}^{-1}$ for UGAB sources in glass vials and $(544.45 \pm 0.44) \mathrm{kBq} \mathrm{g}^{-1}$ for UG sources in plastic vials. The $95 \%$ confidence interval for the difference between the means is $(0.49 \pm 1.18) \mathrm{kBq} \mathrm{g}^{-1}$. Hence, the difference is not significant at $5 \%$. For $F=1.18$ with $v=5$ and $v=8$ degrees of freedom, the probability value for the $F$ test is $p=0.39$. The critical values of $F$ in this case are $F(\alpha=0.01)=7.01$ and $F(\alpha=0.05)=3.84$.

Examination of the results from Trials 1 through 8 (all with cocktails prepared from UGAB in glass) also reveals the invariance for the sampling from three different ampoules of SRM 4927G. The mean values with their $95 \%$ confidence intervals for ampoules \#113, \#172, and \#47 are $(544.3 \pm 1.7) \mathrm{kBq}$

$\mathrm{g}^{-1},(542.9 \pm 2.1) \mathrm{kBq} \mathrm{g}^{-1}$, and $(544.2 \pm 2.6) \mathrm{kBq} \mathrm{g}^{-1}$, respectively, where the confidence intervals were formed from the product of the Student- $t$ value for the limited $v=2$ and $v=1$ degrees of freedom and the standard deviation of the mean.

Hence, it is evident that the $\overline{\bar{A}}$ results given in Table 4 are invariant with the counter used, as well as with the different source compositions, and with the ampoule sampled.

\subsection{SRM 4926E}

The comparisons of SRM 4926E with respect to SRM 4927F provides a useful confirmation of the consistency between SRM 4927G and SRM 4927F. These results are given in Table 5. The comparison value of $\overline{\bar{A}}=1.9737 \mathrm{kBq} \mathrm{g}^{-1}$, with $S=0.20 \%$, on considering only the measurement imprecision uncertainty, can be compared to the decay-corrected certified value for SRM 4926E (Table 1). They agree to $+0.07 \%$.

The present comparison ratio of SRM 4927F to SRM 4926E, having a value of $125.90 \pm 0.26$, can also be examined with respect to the values given by Lucas [1] for the ratio obtained from a dilution factor and from comparative LS measurements. These are $125.880 \pm 0.062$ and $125.959 \pm 0.052$, respectively. The uncertainties for the LS-based ratios given here correspond to a standard deviation of the mean. The Lucas ratio based on gravimetric dilution is a canonical $k=1$ standard uncertainty of 0.05 $\%$. The Lucas LS-based ratio for the standard deviation of the mean is for $n=7$ determinations. Its relatively small relative uncertainty $(0.041 \%)$ arises from the small number of LS comparisons of closely matched counting sources under limited changes in conditions or variables. The comparison ratio for SRM 4927F to SRM 4926E found here agrees with values of Lucas to $+0.01 \%$ and $-0.05 \%$. These 
agreements reflect that SRM 4927G is equally consistent with a calibration against the decay-corrected certified value of SRM 4926E as to the calibration with SRM 4927F.

\subsection{F1994 and F2009}

The results for the two French solutions with respect to efficiency tracing with SRM 4927F are given in Tables 6 and 7. The decay-corrected values from French documentation [11, 12, 14, 20] differ from the present determinations by $+1.0 \%$ for F1994 and by $-1.6 \%$ for F2009. The relative combined standard uncertainties on the measured NIST values for the two solutions are estimated by combining the precision estimators in Tables 6 and 7 with additional components of uncertainty (see, e.g., Table 8) to be approximately $0.56 \%$. On propagating these with the uncertainties on the French values (Table 1), the relative combined uncertainty on the French/NIST ratios are $0.80 \%$ and $0.82 \%$, respectively, for F1994 and F2009. Though the LS measurements can be considered to be in agreement with the French values to within a $95 \%(k=2)$ confidence interval, their differences are still surprisingly disconcerting, particularly since the F1994 solution was previously measured by NIST.

The F1994 solution was identical to that used for the comparison in 1995-1996 of NIST SRM 4927E with this French national standard [11]. At that time, it was found that the LPRI standard differed from the NIST one by $+0.37 \%$, with both standards having relative standard uncertainties of about $0.5 \%$. Given that the ${ }^{3} \mathrm{H}$ massic activity ratio of SRM 4927F to SRM 4927E was well characterized by Lucas [1], the difference between the former measurement of F1994 against SRM 4927E (+ 0.37\%) and the current determination against 4927F $(+1.0 \%)$ was unexpected and is inexplicable, even with the passage of nearly 20 years.

The decay-corrected KCRV for F2009, as obtained from an analysis of 15 results from the CCRI(II) international comparison [14] is $(26.594 \pm 0.127) \mathrm{kBq} \mathrm{g}^{-1}$. The $k=1$ uncertainty on this value is $0.48 \%$, and the value itself agrees with the comparison to SRM 4927F to $-0.26 \%$, which indicates excellent agreement.

The decay-corrected, reported French values (Table 1) for F1994 and F2009 have a ratio of (63.40/ $26.25)=2.415$, with a relative combined $k=1$ uncertainty of $0.83 \%$. The ratio, however, as obtained from tracing with SRM 4927F is $(62.743 / 26.664)=2.3531$, with a relative combined $k=1$ uncertainty of $0.79 \%$. With this, the present LS comparison measurements suggest that the reported French values are in disagreement with each other to about $2.6 \%$. The $-1.6 \%$ difference between the French value for 
F2009 and SRM 4927F is essentially of similar magnitude (-1.3\%) as the difference in the LNHB value from the KCRV.

The F1994 to F2009 massic activity ratio could be obtained directly from the respective counting data in Trials 11 through 14 without tracing against SRM 4927F. The approach gives a much lower uncertainty because of the removal of duplicate and correlated uncertainties. This was done, within each trial, by fitting the decay- and background-corrected, massic activities for the counting sources and their corresponding quench indicating parameters $\mathrm{Q}$ to a second-order polynomial. The two resulting functions $f(Q)$ for F1994 and F2009 were then numerically evaluated at 48 equally-spaced $Q$ values in the $Q$ range of the measurements for that trial. The ratio of $f_{\mathrm{F} 1994}(Q) / f_{\mathrm{F} 2009}(Q)$ at each of the $48 Q$ values was then averaged for the trial. The mean ratio for all four trials was 2.3528 , with a between-trial relative standard deviation of $0.083 \%$ and a typical within-trial standard deviation of the mean of $0.015 \%$ that propagates to $0.085 \%$ at $k=1$. This reproduces the ratio obtained from efficiency tracing with SRM 4927F.

\section{Certification of SRM 4927G}

The prepared and calibrated tritiated water solution standards were certified and will be disseminated as NIST SRM 4927G with the following specifications:

$\begin{array}{ll}\text { Radionuclide: } & \text { Hydrogen-3 } \\ \text { Reference time: } & 1200 \text { EST, 1 May } 2015 \\ \text { Massic activity: } & 544.2 \mathrm{kBq} \mathrm{g}^{-1} \\ \text { Relative expanded }(k=2) \text { uncertainty: } & 0.96 \%\end{array}$

The solution was also characterized in terms of the following uncertified information:

Source description: Liquid in a 5-mL, flame-sealed, borosilicate-glass ampoule

Solution composition: $\quad$ Distilled water as $\mathrm{H}_{2} \mathrm{O}$ and ${ }^{3} \mathrm{H}^{1} \mathrm{HO}$

Solution density: $\quad(0.998 \pm 0.001) \mathrm{g} \mathrm{mL}^{-1}$ at $21.6{ }^{\circ} \mathrm{C}$

Solution mass: $\quad(4.99 \pm 0.01) \mathrm{g}$ 


$$
\begin{array}{ll}
\text { Radionuclidic impurities: } & \text { None detected (see Annex A) } \\
{ }^{3} \mathrm{H} \text { half-life: } & (12.312 \pm 0.025) \text { a }[24]
\end{array}
$$

The uncertainty assessment for the ${ }^{3} \mathrm{H}$ massic activity for SRM $4927 \mathrm{G}$ is summarized in Table 8 .

This calibration of SRM 4927G by efficiency tracing with SRM 4927F was confirmed by consistency with SRM 4926E (to within $0.07 \%$ ) and with the KCRV for ${ }^{3} \mathrm{H}$ in the CCRI(II) comparison (to within $0.26 \%$ ). In addition, a completely independent confirmation was obtained from determinations of the massic activity of both SRM 4927F and SRM 4927G by TDCR measurements, as reported in Annex B. These were in agreement to $-0.24 \%$ and $-0.27 \%$, respectively. The ratio of the massic activities of SRM 4927F to SRM 4927G from the TDCR determinations agreed with the ratio of certified values to $-0.03 \%$.

\section{Summary}

The $17^{\text {th }}$ issue of a NIST tritiated-water standard, SRM 4927G, was calibrated for ${ }^{3} \mathrm{H}$ massic activity by LS efficiency tracing with SRM 4927F, which in turn was standardized by internal proportional gas counting in 1998. This SRM has a relative $k=2$ expanded uncertainty of just under $\pm 1 \%$. The new standard was also shown through LS comparison measurements to be consistent with SRM 4926E to within $0.07 \%$ and with an internationally-based KCRV to within $0.26 \%$ as evaluated by comparison with the F2009 solution used in the CCRI(II) key comparison [14]. Table 9 summarizes the overall agreement between standards. Contemporaneous independent measurements by TDCR counting (Annex B) confirmed the standardization of both SRM 4927F and SRM 4927G. Even though the TDCR determinations have relative $k=2$ uncertainties of about $\pm 2.6 \%$, the results agree with the SRM certified values to $-0.24 \%$ and $-0.27 \%$ for SRM 4927F and SRM 4927G, respectively. The relative uncertainty in the ratio of the two standards by TDCR counting is considerably lower; viz., $\pm 0.76 \%$ for a $k=2$ interval. The massic activity ratio for SRM 4927G to SRM 4927F by TDCR counting agrees with the ratio of certified values to $-0.03 \%$. This provides another consistency link between SRM 4927G and SRM 4927F.

A curious finding of these comparative LS measurements was an apparent $2.6 \%$ discrepancy between the reported values for F1994 and F2009 solutions, which represent the LPRI 1994 standard [11, 12] and 2009 measurements by LNHB for a CCRI(II) international comparison $[14,20]$. The $-1.3 \%$ difference between the LNHB comparison result and the KCRV for solution F2009 was also revealed in the LS 
comparison measurements presented here. The slight apparent inconsistency, yet within uncertainty intervals, in the NIST measurements on the F1994 solution for the current LS comparison results (+1.0 $\%)$ and those made in 1995-1996 (+0.4\%) is also somewhat unsettling, but perhaps not unreasonable given the magnitude of the inherent uncertainties as well as the passage of 20 years between the determinations.

\section{ANNEX A: Radionuclidic impurity analyses for SRM 4927G}

The LS spectra of SRM 4927G (see, for example, Figs. 3 and 4) demonstrate that there are no apparent radionuclidic impurities with radiations above the approximate $20 \mathrm{keV}{ }^{3} \mathrm{H}$ beta spectrum endpoint energy. The integral regions above the ${ }^{3} \mathrm{H}$ windows were investigated in four specific cases to set an upper limit on a possible impurity level. They were for the least and most quenched sources in a series set on both the Beckman B and Wallac W counters. On assuming that any count in the region above the ${ }^{3} \mathrm{H}$ window was from a decay event from an impurity that was detected with $100 \%$ efficiency and that the governing statistics were that of a Poisson process, then the net massic activity of an impurity relative to that of ${ }^{3} \mathrm{H}$ were found to be:

$(0.0007 \pm 0.0010) \%$ for the least quenched source in the Beckman counter B

(- $0.0015 \pm 0.0010) \%$ for the most quenched source in the Beckman counter B

$(0.0011 \pm 0.0010) \%$ for the least quenched source in the Wallac counter $\mathrm{W}$

$(0.0004 \pm 0.0009) \%$ for the most quenched source in the Wallac counter $\mathrm{W}$

These results average to $(0.0002 \pm 0.0005) \%$. The uncertainties given here for the relative massic activities are one standard deviations for a Poisson distribution.

Impurity analyses of the SRM 4927G solution were also performed by high-resolution photonic emission spectrometry using high-purity germanium (HPGe) detectors. For this, the contents of a SRM 4927G series ampoule were transferred gravimetrically to a standard NIST $5 \mathrm{~mL}$ borosilicate ampoule, which is used to define geometry and attenuation for all ionization chamber and gamma-ray spectrometry measurements performed at NIST. Two long-term counting measurements were made. The first, for a counting duration of $1.07 \mathrm{~d}$, was with detector " $\mathrm{X}$ " and the ampoule in a side-mount geometry. The second was for $8.82 \mathrm{~d}$ with the ampoule on a side mount with detector "G." The detectors and spectrometry procedures used by NIST have been described by Pibida, et al. [27, 28]. 
No photon-emitting impurities were observed in either measurement. The detection limit for the first measurement in the energy region $30 \mathrm{keV}<E<2000 \mathrm{keV}$ was estimated to be $0.38 \mathrm{~s}^{-1} \mathrm{~g}^{-1}$, which is less than $7 \times 10^{-5} \%$ of the ${ }^{3} \mathrm{H}$ massic activity of SRM $4927 \mathrm{G}$. The second and longer measurement had estimated limits of:

$$
\begin{aligned}
& 0.13 \mathrm{~s}^{-1} \mathrm{~g}^{-1} \text { for } 25 \mathrm{keV}<E<45 \mathrm{keV} \\
& 0.06 \mathrm{~s}^{-1} \mathrm{~g}^{-1} \text { for } 50 \mathrm{keV}<E<1430 \mathrm{keV} \\
& 0.09 \mathrm{~s}^{-1} \mathrm{~g}^{-1} \text { for } 1440 \mathrm{keV}<E<1480 \mathrm{keV} \\
& 0.05 \mathrm{~s}^{-1} \mathrm{~g}^{-1} \text { for } 1490 \mathrm{keV}<E<2000 \mathrm{keV} .
\end{aligned}
$$

These limits are in the range of $2 \times 10^{-5} \%$ to $8 \times 10^{-6} \%$, relative to the ${ }^{3} \mathrm{H}$ massic activity.

\section{ANNEX B: Confirmatory Measurements by LS TDCR}

Independent confirmatory measurements by TDCR counting were performed on both SRM 4927F and $4927 \mathrm{G}$ solutions. The results were obtained in blind to the origin of the ${ }^{3} \mathrm{H}$ solutions and the other comparison measurements.

The sources from Series V and VII (see Table 3) were measured on the NIST custom TDCR counter, which has been described previously by Zimmerman et al. [29]. Data were acquired simultaneously using a MAC3 module [30] and an FPGA ${ }^{10}$-based system. Efficiency variation was achieved by chemical quenching with nitromethane (see Sect 2.3 and Table 3); no gray filters were used. A preset livetime of $600 \mathrm{~s}$ was set for all acquisitions that resulted in the logical sum of doubles events of about $5 \times 10^{5}$ counts to $6.4 \times 10^{5}$ counts for each trial, which corresponds to a relative Poisson statistical counting error of < $0.1 \%$. Experimental TDCR values $(K)$ ranged from approximately 0.33 to 0.40 . Recently, attention has been devoted to the importance of using a sufficiently long coincidence resolving time $\tau$ for TDCR counting of ${ }^{3} \mathrm{H}$ and other low-efficiency radionuclides [31-33]. For this work, all FPGA counting was performed with $\tau=200 \mathrm{~ns}$. The doubles rate at $\tau=40 \mathrm{~ns}$, as used in the MAC3 module, was about $3 \%$ lower than at $\tau=200 \mathrm{~ns}$. Because $K$ was similarly dependent on the doubles rate, recovered activities were not as dependent on $\tau$ as might have been expected. To evaluate the precision of repeated measurements the most quenched source from each of the two solutions was counted overnight for 75 successive 600 -second acquisitions, in which the doubles counting rates decreased by $<0.5 \%$ in all cases.

The first set of measurements with Series V (Table 3) over longer time intervals exhibited the cocktail instability that was noted previously (Sections 2.3 and 3.2). Over a 2-day period, the doubles rate

\footnotetext{
${ }^{10}$ field-programmable gate array (FPGA).
} 
decreased by approximately $4 \%$. This was accompanied by a drop in the measured $K$ as well, so the recovered activity over the same 2 days decreased by $<0.5 \%$. The instability was considered worrisome enough, however, to exclude any results from this source series.

The sources for Series VII (Table 3) exhibited greater stability with time. For the most quenched sources, the doubles rates decreased on an average of $<1 \%$ over 2 days. The counting scheme consisted of the following. For each solution, the 6 sources - two each at three levels of quenching — were measured three times on three separate measurement occasions. Evaluations were made by consideration of the within-measurement and between-measurement variations on each source and the within-source and between-source variations.

All efficiency calculations were performed with the MICELLE2 code [34-36]. For each calculation, 50000 events were simulated. The input data file was edited to reflect the appropriate aqueous content of the samples. The micelle correction, which has been shown to be negligible for the cocktails used here [37, 38], was not incorporated. Calculations were run with various values for Birk's parameter $k B$ and for the beta endpoint energy $E_{\beta \max }$ in order to assess the effect of these input data on the uncertainty on the recovered activity. The doubles efficiency $\varepsilon$ and $K$ values, from the MICELLE2 output file, were fit to second-order polynomials using a least squares approach. In turn, the fitted functions of $\varepsilon$ as a function of $K$ were used to calculate the $\varepsilon$ values from the measured values of $K$. The error on the fit contributed negligibly to the uncertainty on the recovered activity. The massic activity for each source measurement was derived from the background- and decay-corrected doubles rate, the source aliquant mass, and the efficiency value $\varepsilon$ that was calculated from the measured $K$.

The determined values for the ${ }^{3} \mathrm{H}$ massic activity in SRM 4927F and SRM 4927G were $248 \mathrm{kBq} \mathrm{g}^{-1}$ and $543 \mathrm{kBq} \mathrm{g}^{-1}$, respectively. Their relative expanded $(k=2)$ uncertainties are estimated to be $2.6 \%$ and $2.7 \%$. The uncertainty assessment is summarized in Table A1. Despite, the large uncertainties associated with these results, the two TDCR determinations are in agreement with the certified values of SRM 4927F [18] and SRM 4927G (Section 4) to $-0.24 \%$ and $-0.27 \%$, respectively. The ratio of the two standards, determined with a substantially smaller relative uncertainty of $0.76 \%$ at $k=2$, agrees with the ratio of the certified values to $-0.03 \%$.

The largest uncertainty component for the massic activity determinations arises from the sensitivity of the results to $k B$. For $k B \gtrsim 0.009 \mathrm{~cm} \mathrm{MeV}^{-1}$, the recovered massic activities $A$ for a set of chemically quenched sources showed clear trending (decreasing monotonically) with increasing $\varepsilon$ (i.e., with $K$ ). Over the range of $k B=0.005 \mathrm{~cm} \mathrm{MeV}^{-1}$ to $0.009 \mathrm{~cm} \mathrm{MeV}^{-1}$, the recovered $A$ showed a $4 \% \mathrm{kB}$-dependence, but 
never showed a trend with $K$. For the final analysis, the recommended value of $k B=0.0075 \mathrm{~cm} \cdot \mathrm{MeV}^{-1}$ was used [36]. The between-source standard deviations provide some measure of "model goodness" since the differently quenched sources sample different $\varepsilon$ values. These standard deviations reached apparent minima and the slopes of the $A$ vs. $K$ curves were closest to zero at $k B \approx 0.006 \mathrm{~cm} \cdot \mathrm{MeV}^{-1}$. These criteria could also have been used as an alternative approach to $k B$ selection. The calculated massic activities obtained using this smaller $k B$ decrease by about $1.5 \%$ compared to those with $k B=0.0075 \mathrm{~cm} \cdot \mathrm{MeV}^{-1}$. Crucially, the $k B$ sensitivity of $A$ does not significantly impact the massic activity ratio for the two standards. As reflected in Table A1, $k B$ sensitivity contributes an uncertainty of $1.3 \%$ for the individual standards, but only $0.006 \%$ for the ratio. 


\section{Acknowledgements}

The continual advice, critical commentary, and devil's advocacy by Ryan Fitzgerald throughout the course of this work was greatly appreciated. He must also be credited with creating and developing the novel and unique Fitzgerald plot, and executing it with the present data as shown in Figure 7. Daniel Golas assisted in the tedious task of flame sealing 175 ampoules. Leticia Pibida is acknowledged and thanked for performing the impurity analyses by photonic emission spectrometry. Philippe Cassette (Laboratoire National Henri Becquerel) provided the French tritiated water solution in 1994 as well as a replacement ampoule of the solution used for the 2009 international comparison. The National Institute of Standards and Technology is an agency of the U.S. Department of Commerce. 


\section{References}

[1] Lucas L L 2000 Massic Activity Ratios of the NBS/NIST Tritiated-Water Standards Issued Between 1954 and 1999 J. Res. Natl. Inst. Stds. Tech. 105, 535-539.

[2] Garfinkel S B, Mann W B, Schima F J, Unterweger M P 1973 Present status in the field of internal gas counting, Nucl. Instr. Meth. 112, 59-67

[3] Unterweger M P 2007 Primary radioactive gas standards (excluding radon), Metrologia 44, S79-S81

[4] Unterweger M, Johansson L, Karam L, Rodrigues M, Yunoki A 2015 Uncertainties in internal gas counting, Metrologia 52, S156-S164

[5] Mann W B 1973 The Calibration of the National Bureau of Standards Tritium Standards by Microcalorimetry and Gas Counting (Proceedings Tritium Symposium, Las Vegas, 1971), Chapter 3, Detection and Measurement, in A.A. Moghissi, M.W. Carter (eds.), Messenger Graphics, Phoeniz, AZ

[6] National Bureau of Standards (NBS) 1961 Certificate NBS 4927, Beta-Ray Standard, Hydrogen-3, NBS, Washington, DC, 1954; revised certificate

[7] Unterweger M P, Coursey B M, Schima F J, Mann W B 1980 Preparation and calibration of the 1978 National Bureau of Standards tritiated-water standards, Int. J. Appl. Radiat. Isot. 31, 611-614

[8] Unterweger M P, Lucas L L 2000 Calibration of the National Institute of Standards and Technology tritiated-water standards, Appl. Radiat. Isot. 52, 527-531

[9] Makepeace J L, Day F E, Gunther E, Unterweger M P 1996 Intercomparison of measurement of tritiated water by internal proportional gas counting, Nucl. Instr. Meth. A369, 458-462

[10] Makepeace J, Altzitzoglou T, Cassette P, Dryak P, Gunther E, Verrezen F, Broda R, Simpson B, Unterweger M, 1998 International Comparison of Measurements of the Specific Activity of Tritiated Water, Appl. Radiat. Isot. 49, 1411-1416

[11] Zimmerman B E, Collé R 1997 Comparison of the French and U.S. National ${ }^{3} \mathrm{H}$ (tritiated $\mathrm{H}_{2} \mathrm{O}$ ) Standards by $4 \pi \beta$ Liquid Scintillation Spectrometry Appl. Radiat. Isot. 48, 521-526

[12] Laboratoire Primaire des Rayonnements Ionisants (LPRI) 1994 Certificate d'etalonnage no. 94/R007E, LPRI, Gif-Sur-Yvette, France

[13] National Institute of Standards and Technology (NIST) 1995 Certificate, Standard Reference Material 4927E, Hydrogen-3 Radioactivity Standard, NIST Gaithersburg, MD, USA

[14] Ratel G, 2015 International comparison of activity measurements of a solution of tritiated water, Comité Consultatif des rayonnements Ionisants CCRI(II) Report CCRI(II)-K2.H-3 (Draft B, 3 april 2015), Bureau International des Poids et Mesures, Sévres, France 
[15] Taylor B N Kuyatt C E 1994 Guidelines for Evaluating and Expressing the Uncertainty of NIST Measurement Results NIST Technical Note 1297, National Institute of Standards and Technology, Gaithersburg, MD

[16] Joint Committee for Guides in Metrology (JCGM) 2008 Guide to the expression of uncertainty in measurement (GUM), JCGM 100:2008

[17] Collé R, Fitzgerald R P, Laureano-Perez L 2015 Development of an Ultra-Pure, Carrier-Free ${ }^{209}$ Po Solution Standard, J. Res. Natl. Inst. Stds. Tech. 120 138-163

[18] National Institute of Standards and Technology (NIST), Certificate, Standard Reference Material 4927F, Hydrogen-3 Radioactivity Standard, NIST Gaithersburg, MD, USA, revised May 2008.

[19] National Institute of Standards and Technology (NIST), Certificate, Standard Reference Material 4926E, Hydrogen-3 Radioactivity Standard, NIST Gaithersburg, MD, USA, revised February 2011.

[20] Jean-Baptise P, Cassette P, Fourré E, Tartès I, Dapoigny A 2014 Measurement of the French national tritiated-water standard by helium-3 mass spectrometry Appl. Radiat. Isot. 87 157-161

[21] Bergeron D E 2012 Determination of micelle size in some commercial liquid scintillation cocktails, Appl. Radiat. Isot. 70, 2164-2169

[22] Laureano-Perez L, Collé R., Fitzgerald R, Outola, I, Pibida L 2007 A liquid-scintillation-based primary standardization of ${ }^{210} \mathrm{~Pb}$, Appl. Radiat. Isot. 65, 1368-1380

[23]

https://www.perkinelmer.com/Resources/TechnicalResources/ApplicationSupportKnowledgebase/radiom etric/quench.xhtml, PerkinElmer technical resource accessed February 2016

[24] Chechev V P $2006{ }^{3} \mathrm{H}$ - Comments on Evaluation of Decay Data. Recommended data for decay of hydrogen-3, Laboratoire National Henri Becquerel, http://www.nucleide.org/DDEP_WG/Nuclides/H3_com.pdf, DDEP data base accessed July 2015

[25] Filliben J J 1975 The Probability Plot correlation Test for Normality, Technometrics 17, no. 1, 111117

[26] National Institute of Standards and Technology (NIST), Statistical engineering Division, Software, DATAPLOT, Anderson-Darling Goodness of Fit Test, Wilks Shapiro Normality Test, http://www.itl.nist.gov/div898/software/dataplot/ April, 2014.

[27] Pibida L, Hsieh E, Fuentes-Figueroa A, Hammond M M, Karam L 2006 Software studies for germanium detector data analysis, Appl. Radiat. Isot. 64, 1313-1318 
[28] Pibida L, Nafee S S, Unterweger M, Hammond M M, Karam L, Abbas M I 2006 Calibration of HPGe gamma-ray detectors for measurement of radioactive noble gas sources, Appl. Radiat. Isot. 65, $225-233$

[29] Zimmerman B E, Collé R, Cessna J T 2004 Construction and implementation of the NIST triple-todouble coincidence ratio (TDCR) spectrometer, Appl. Radiat. Isotop. 60, 433-438

[30] Bouchard J, Cassette P 2000 MAC3: an electronic module for the processing of pulses delivered by a three phtomultiplier liquid scintillation counting system Appl. Radiat. Isotop. 52, 669-672

[31] Steele T, Mo L, Bignell L, Smith M, Alexiev D 2009 FASEA: A FPGA Acquisition System and Software Event Analysis for liquid scintillation counting, Nucl. Instr. Meth A 609, 217-220

[32] Bobin C, Bouchard J, Censier B 2010 First results in the development of an on-line digital counting platform dedicated to primary measurements, Appl. Radiat. Isot. 68, 1519-1522

[33] Bobin C, Thiam C, Chauvenet B, Bouchard J 2012 On the stochastic dependence between photomultipliers in the TDCR method, Appl. Radiat Isot 70, 770-780

[34] Grau Carles A 2007 MICELLE, the micelle size effect on the LS counting efficiency, Comp. Phys. Comm. 176, 305-317

[35] Kossert K, Grau Carles A 2008 Study of a Monte Carlo rearrangement model for the activity determination of electron-capture nuclides by means of liquid scintillation counting, Appl. Radiat. Isotop. 66, 998-1005

[36] Kossert K, Grau Carles A 2010. Improved method for the calculation of the counting efficiency of electron-capture nuclides in liquid scintillation samples, Appl. Radiat. Isotop. 68, 1482-1488

[37] Bergeron D E 2012 Determination of micelle size in some commercial liquid scintillation cocktails, Appl. Radiat. Isotop. 70, 2164-2169

[38] Bergeron D E, Laureano-Pérez L 2014 Micelle size effect on Fe-55 liquid scintillation efficiency, Appl. Radiat. Isotop. 87, 282-286 
Table 1. Summary of the tritiated-water standards used for comparison with SRM 4927G, with decay to the comparison reference time of 1200 EST, 1 May 2015 using a ${ }^{3} \mathrm{H}$ half-life of (12.312 \pm 0.025$)$ a.

\begin{tabular}{|c|c|c|c|c|}
\hline Identification & $4927 \mathrm{~F}$ & $4926 \mathrm{E}$ & F1994 & F2009 \\
\hline Origin & $\begin{array}{c}\text { NIST } \\
\text { SRM 4927F }\end{array}$ & $\begin{array}{c}\text { NIST } \\
\text { SRM 4926E }\end{array}$ & $\begin{array}{l}\text { LPRI standard 94/R- } \\
\text { 007E, ampoule } \\
\text { distributed as efficiency } \\
\text { monitor for EUROMET } \\
\text { comparison }\end{array}$ & $\begin{array}{l}\text { ampoule LNHB 11-07 } \\
\# 24 \text {, distributed for } \\
\text { CCRI(II) tritiated water } \\
\text { comparison }\end{array}$ \\
\hline Reference & [18] & [19] & {$[12],[11]$} & [14], [20] \\
\hline $\begin{array}{c}\text { Reported } \\
\text { reference time }\end{array}$ & $\begin{array}{c}1200 \text { EST } \\
3 \text { Sept. } 1998\end{array}$ & $\begin{array}{c}1200 \text { EST } \\
3 \text { Sept. } 1998\end{array}$ & $\begin{array}{c}1200 \text { UT } \\
\text { 27 Jan. } 1994\end{array}$ & $\begin{array}{c}1200 \text { UT } \\
31 \text { May } 2009\end{array}$ \\
\hline $\begin{array}{c}\text { Reported } \\
\text { massic activity } \\
\left(\mathrm{kBq} \mathrm{g}^{-1}\right)\end{array}$ & 634.7 & 5.038 & 209.8 & $36.62^{*}$ \\
\hline $\begin{array}{l}\text { Reported } \\
\text { relative standard } \\
\text { uncertainty }(\%)\end{array}$ & 0.36 & 0.36 & 0.52 & 0.60 \\
\hline $\begin{array}{c}\text { Comparison } \\
\text { reference time } t_{0}\end{array}$ & $\begin{array}{c}1200 \text { EST } \\
1 \text { May } 2015\end{array}$ & $\begin{array}{c}1200 \text { EST } \\
1 \text { May } 2015\end{array}$ & $\begin{array}{c}1200 \text { EST } \\
1 \text { May } 2015\end{array}$ & $\begin{array}{c}1200 \text { EST } \\
1 \text { May } 2015\end{array}$ \\
\hline $\begin{array}{c}{ }^{3} \mathrm{H} /{ }^{1} \mathrm{H} \text { mole ratio } \\
\text { at } t_{0}\end{array}$ & $2.89 \times 10^{-9}$ & $2.29 \times 10^{-11}$ & $7.36 \times 10^{-10}$ & $3.05 \times 10^{-10}$ \\
\hline $\begin{array}{c}\text { Massic activity at } t_{0} \\
\left(\mathrm{kBq} \mathrm{g}^{-1}\right)\end{array}$ & 248.5 & 1.972 & 63.40 & 26.25 \\
\hline $\begin{array}{c}\text { Relative standard } \\
\text { uncertainty at } t_{0}(\%)\end{array}$ & 0.41 & 0.41 & 0.57 & 0.60 \\
\hline
\end{tabular}

This is the reported value for the LNHB laboratory based on four measurement methods. Twenty-two independent results from 19 laboratories for the CCRI(II) international comparison had an arithmetic mean of $(36.62 \pm 0.48) \mathrm{kBq} \mathrm{g}^{-1}$. The Key Comparison Reference Value (KCRV), based on 15 results (one per laboratory, with one outlier excluded) obtained with the power-moderated weighted mean formulism [14], was $(37.105 \pm 0.177) \mathrm{kBq} \mathrm{g}^{-1}$, which was in excellent agreement with the arithmetic mean of the 15 values, $(37.15 \pm 0.19) \mathrm{kBq} \mathrm{g}^{-1}$. 
Table 2. Dilution factors $D$ for SRM 4927F and three ampoules (\#113, \#172, and \#47) of SRM 4927G as obtained from the contained mass of the total dilution $m_{\mathrm{c}(\mathrm{tot})}$ divided by the dispensed mass of an aliquant of the tritiated-water solution $m_{\mathrm{d}(\text { (sol). }}$. The mass residuals in $\%$ reflect the relative differences between the contained and dispensed masses, i.e., $m_{\mathrm{c}(\mathrm{tot})}$ compared to $m_{\mathrm{d}(\mathrm{tot})}$ and $m_{\mathrm{c}(\mathrm{sol})}$ to $m_{\mathrm{d}(\mathrm{sol}) \text {. }}$

\begin{tabular}{|c|c|c|c|}
\hline \multirow{2}{*}{$\begin{array}{c}\text { Tritiated-water } \\
\text { solution }\end{array}$} & \multirow{2}{*}{$D$} & \multicolumn{2}{|c|}{ Relative mass residuals / \% } \\
\cline { 2 - 4 } & 9.6751 & Total mass & Solution aliquant \\
\hline $4927 \mathrm{~F}$ & 24.362 & -0.008 & -0.037 \\
\hline 4927G-113 & 22.805 & -0.009 & -0.078 \\
\hline 4927G-172 & 16.845 & -0.007 & -0.070 \\
\hline $4927 \mathrm{G}-47$ & & +0.003 & +0.075 \\
\hline
\end{tabular}


Table 3. Characteristics of the LS cocktail counting sources in terms of preparation details.

\begin{tabular}{|c|c|c|c|c|c|c|c|c|}
\hline series & $\begin{array}{c}\text { prepared } \\
\text { (2015 day) }\end{array}$ & $\begin{array}{l}\text { scintillant } \\
\& \text { vial }\end{array}$ & solutions & $n$ & $\begin{array}{c}m_{3} / \mathrm{mg} \\
\text { range }\end{array}$ & $\begin{array}{l}m_{\mathrm{tot}} / \mathrm{g} \\
\text { range }\end{array}$ & $\begin{array}{c}f_{\text {aq }} / \% \\
\text { range }\end{array}$ & $\begin{array}{c}N_{\mathrm{Q}} / \mathrm{mmol} \\
\text { range }\end{array}$ \\
\hline I & 110 & $\begin{array}{l}\text { UGAB } \\
\text { glass }\end{array}$ & $\begin{array}{c}4927 \mathrm{G}-113 \\
4927 \mathrm{~F} \\
\text { F2009 }\end{array}$ & $\begin{array}{l}5 \\
6 \\
6\end{array}$ & $\begin{array}{l}87 \text { to } 101 \\
89 \text { to } 116 \\
34 \text { to } 111\end{array}$ & $\begin{array}{c}10.69 \\
\text { to } \\
10.86\end{array}$ & $\begin{array}{c}6.3 \\
\text { to } \\
7.2\end{array}$ & $\begin{array}{c}0.07 \\
\text { to } \\
0.59\end{array}$ \\
\hline II & 120 & $\begin{array}{l}\text { UGAB } \\
\text { glass }\end{array}$ & $\begin{array}{c}\text { 4927G-172 } \\
\text { 4927F } \\
\text { F1994 }\end{array}$ & $\begin{array}{l}5 \\
6 \\
6\end{array}$ & $\begin{array}{c}92 \text { to } 141 \\
105 \text { to } 111 \\
42 \text { to } 45\end{array}$ & $\begin{array}{c}10.61 \\
\text { to } \\
10.78\end{array}$ & $\begin{array}{c}6.1 \\
\text { to } \\
6.8\end{array}$ & $\begin{array}{c}0.06 \\
\text { to } \\
0.63\end{array}$ \\
\hline III & 149 & $\begin{array}{l}\text { UGAB } \\
\text { glass }\end{array}$ & $\begin{array}{c}4927 \mathrm{G}-47 \\
4927 \mathrm{~F} \\
4926 \mathrm{E}\end{array}$ & $\begin{array}{l}6 \\
6 \\
6\end{array}$ & $\begin{array}{l}100 \text { to } 128 \\
90 \text { to } 101 \\
689 \text { to } 720\end{array}$ & $\begin{array}{c}10.64 \\
\text { to } \\
10.73\end{array}$ & $\begin{array}{c}6.2 \\
\text { to } \\
6.7\end{array}$ & $\begin{array}{c}0.03 \\
\text { to } \\
0.30\end{array}$ \\
\hline IV & 167 & $\begin{array}{c}\text { UG } \\
\text { plastic }\end{array}$ & $\begin{array}{c}4927 \mathrm{G}-172 \\
4927 \mathrm{~F} \\
\text { F2009 } \\
\text { F1994 }\end{array}$ & $\begin{array}{l}6 \\
6 \\
6 \\
6\end{array}$ & $\begin{array}{c}108 \text { to } 131 \\
96 \text { to } 132 \\
89 \text { to } 111 \\
30 \text { to } 53\end{array}$ & $\begin{array}{c}10.05 \\
\text { to } \\
10.16\end{array}$ & $\begin{array}{l}1.9 \\
\text { To } \\
2.7\end{array}$ & $\begin{array}{c}0.04 \\
\text { to } \\
0.37\end{array}$ \\
\hline V & 167 & $\begin{array}{c}\text { UG } \\
\text { plastic }\end{array}$ & $\begin{array}{c}\text { 4927G-172 } \\
4927 \mathrm{~F}\end{array}$ & $\begin{array}{l}3 \\
3\end{array}$ & $\begin{array}{l}110 \text { to } 114 \\
103 \text { to } 157\end{array}$ & $\begin{array}{c}10.06 \\
\text { to } \\
10.14\end{array}$ & $\begin{array}{c}2.2 \\
\text { to } \\
2.9\end{array}$ & $\begin{array}{c}0.03 \\
\text { To } \\
0.17\end{array}$ \\
\hline VI & 188 & $\begin{array}{c}\text { UG } \\
\text { plastic }\end{array}$ & $\begin{array}{c}\text { 4927G-113 } \\
\text { 4927F } \\
\text { F2009 } \\
\text { F1994 }\end{array}$ & $\begin{array}{l}6 \\
6 \\
6 \\
6\end{array}$ & $\begin{array}{c}92 \text { to } 105 \\
71 \text { to } 96 \\
92 \text { to } 117 \\
47 \text { to } 66\end{array}$ & $\begin{array}{c}10.54 \\
\text { to } \\
10.68\end{array}$ & $\begin{array}{l}6.4 \\
\text { To } \\
7.4\end{array}$ & $\begin{array}{c}0.03 \\
\text { To } \\
0.38\end{array}$ \\
\hline VII & 188 & $\begin{array}{c}\text { UG } \\
\text { plastic }\end{array}$ & $\begin{array}{c}4927 \mathrm{G}-113 \\
4927 \mathrm{~F}\end{array}$ & $\begin{array}{l}3 \\
3\end{array}$ & $\begin{array}{l}98 \text { to } 104 \\
81 \text { to } 101\end{array}$ & $\begin{array}{c}10.56 \\
\text { to } \\
10.63\end{array}$ & $\begin{array}{r}6.7 \\
\text { to } \\
7.0\end{array}$ & $\begin{array}{c}0.03 \\
\text { To } \\
0.17\end{array}$ \\
\hline
\end{tabular}

Col. 2: gives the cocktail series preparation date in 2015 Julian Day Number (EST)

Col. 3: scintillant used to prepare the series refers to "UltimaGold AB" (UGAB) or "UltimaGold" (UG) in either glass or plastic LS vials

Col. 4: identifies the ${ }^{3} \mathrm{H}$ solutions (and their dilutions) used to prepare the cocktails in the series (see Tables 1 and 2)

Col. 5: $n$ is the number of cocktails prepared with each solution

Col. 6: $m_{3}$ is the aliquant mass of the ${ }^{3} \mathrm{H}$ solution in the cocktail in milligrams

Col. 6: $m_{\text {tot }}$ is the total mass of the cocktail in grams for the range over all sources in the series

Col. 7: $f_{\mathrm{aq}}$ is the aqueous fraction in terms of the ratio of water mass to total mass of the cocktail for the range over all sources in the series

Col. 8: $N_{\mathrm{Q}}$ is the quantity of the cocktail's $\mathrm{CH}_{3} \mathrm{NO}_{2}$ imposed quenching agent in millimoles for the range over all sources in the series 
Table 4. Grand mean values $\bar{A}$ in units of $\mathrm{kBq} \mathrm{g}^{-1}$ for the massic activity of SRM $4927 \mathrm{G}$ from efficiency tracing with SRM 4927F in 14 measurement trials. Each trial result was based on 5 replicate measurements of $A$ on each of n quench-varied sources. The great-grand mean $\overline{\bar{A}}$ was obtained from the average of the $14 \bar{A}$ values. Refer to text for definitions of the relative precision estimators $s_{\mathrm{B}}, s_{\mathrm{W}}, s_{\mathrm{T}}, S_{\mathrm{B}}, S_{\mathrm{W}}$, and $S$.

\begin{tabular}{|c|c|c|c|c|c|c|}
\hline \multicolumn{2}{|c|}{ SRM 4927G } & \multirow{2}{*}{$\bar{A} / \mathrm{kBq} \mathrm{g}^{-1}$} & \multirow[b]{2}{*}{$s_{\mathrm{B}} / \%$} & \multirow[b]{2}{*}{$s_{\mathrm{W}} / \%$} & \multirow[b]{2}{*}{$s_{\mathrm{T}} / \%$} & \multirow[b]{2}{*}{$\left(s_{\mathbf{T}} / \sqrt{ } \mathbf{n}\right) / \%$} \\
\hline Trial & $n$ & & & & & \\
\hline 1 & 5 & 543.72 & 0.11 & 0.16 & 0.20 & 0.09 \\
\hline 2 & 5 & 544.08 & 0.15 & 0.24 & 0.28 & 0.13 \\
\hline 3 & 5 & 545.02 & 0.13 & 0.15 & 0.20 & 0.09 \\
\hline 4 & 5 & 543.80 & 0.12 & 0.27 & 0.29 & 0.13 \\
\hline 5 & 5 & 542.08 & 0.14 & 0.30 & 0.33 & 0.15 \\
\hline 6 & 5 & 542.95 & 0.14 & 0.39 & 0.41 & 0.18 \\
\hline 7 & 6 & 544.00 & 0.12 & 0.20 & 0.23 & 0.09 \\
\hline 8 & 6 & 544.41 & 0.11 & 0.26 & 0.28 & 0.12 \\
\hline 9 & 6 & 545.34 & 0.11 & 0.24 & 0.27 & 0.11 \\
\hline 10 & 6 & 545.13 & 0.10 & 0.26 & 0.28 & 0.11 \\
\hline 11 & 6 & 543.99 & 0.17 & 1.29 & 1.30 & 0.53 \\
\hline 12 & 6 & 543.12 & 0.11 & 1.47 & 1.47 & 0.60 \\
\hline 13 & 6 & 545.57 & 0.15 & 0.17 & 0.23 & 0.09 \\
\hline 14 & 6 & 545.54 & 0.11 & 0.29 & 0.31 & 0.12 \\
\hline \multicolumn{2}{|c|}{$\overline{\bar{A}} / \mathbf{k B q} \mathbf{g}^{-1}$} & 544.20 & & & & \\
\hline \multicolumn{2}{|c|}{$S_{\mathrm{B}} / \%$} & 0.19 & & & & \\
\hline \multicolumn{2}{|c|}{$S_{\mathrm{W}} / \%$} & 0.15 & & & & \\
\hline \multicolumn{2}{|c|}{$S / \%$} & 0.24 & & & & \\
\hline
\end{tabular}


Table 5. Grand mean values $\bar{A}$ in units of $\mathrm{kBq} \mathrm{g}^{-1}$ for the massic activity of SRM $4926 \mathrm{E}$ from efficiency tracing with SRM 4927F in 4 measurement trials. Each trail result was based on 5 replicate measurements of $A$ on each of 6 quench-varied sources. The great-grand mean $\overline{\bar{A}}$ was obtained from the average of the $4 \bar{A}$ values. Refer to text for definitions of the relative precision estimators $s_{\mathrm{B}}, s_{\mathrm{W}}, s_{\mathrm{T}}, S_{\mathrm{B}}, S_{\mathrm{W}}$, and $S$.

\begin{tabular}{|c|c|c|c|c|c|c|}
\hline \multicolumn{2}{|c|}{ SRM 4926E } & & & & & \\
\hline Trial & $n$ & $\bar{A} / \mathbf{k B q} \mathbf{g}^{-1}$ & $s_{\mathrm{B}} / \%$ & $s_{W} / \%$ & $s_{\mathrm{T}} / \%$ & $\left(s_{\mathrm{T}} / \sqrt{ } 6\right) / \%$ \\
\hline 7 & 6 & 1.9749 & 0.19 & 0.10 & 0.21 & 0.09 \\
\hline 8 & 6 & 1.9708 & 0.35 & 0.11 & 0.37 & 0.15 \\
\hline 9 & 6 & 1.9752 & 0.47 & 0.07 & 0.48 & 0.20 \\
\hline 10 & 6 & 1.9738 & 0.55 & 0.10 & 0.56 & 0.23 \\
\hline$\overline{\bar{A}} / \mathbf{k B q ~ g}^{-1}$ & 1.9737 & & & & & \\
\hline$S_{\mathrm{B}} / \%$ & 0.10 & & & & & \\
\hline$S_{\mathrm{W}} / \%$ & 0.17 & & & & & \\
\hline$S / \%$ & 0.20 & & & & & \\
\hline
\end{tabular}


Table 6. Grand mean values $\bar{A}$ in units of $\mathrm{kBq} \mathrm{g}^{-1}$ for the massic activity of F1994 from efficiency tracing with SRM 4927F in 7 measurement trials. Each trial result was based on 5 replicate measurements of $A$ on each of 6 quench-varied sources. The great-grand mean $\overline{\bar{A}}$ was obtained from the average of the $7 \bar{A}$ values. Refer to text for definitions of the relative precision estimators, $s_{\mathrm{B}}, s_{\mathrm{W}}, s_{\mathrm{T}}, S_{\mathrm{B}}, S_{\mathrm{W}}$, and $S$.

\begin{tabular}{|c|c|c|c|c|c|c|}
\hline \multicolumn{2}{|c|}{ F1994 } & & & & & \\
\hline Trial & $n$ & $\bar{A} / \mathbf{k B q} \mathbf{g}^{-1}$ & $s_{\mathrm{B}} / \%$ & $s_{\mathrm{W}} / \%$ & $s_{\mathrm{T}} / \%$ & $\left(s_{\mathbf{T}} / \sqrt{ } \mathbf{n}\right) / \%$ \\
\hline 4 & 6 & 62.842 & 0.25 & 0.09 & 0.26 & 0.11 \\
\hline 5 & 6 & 62.848 & 0.24 & 0.12 & 0.27 & 0.11 \\
\hline 6 & 6 & 62.813 & 0.35 & 0.10 & 0.36 & 0.15 \\
\hline 11 & 6 & 62.487 & 0.39 & 0.15 & 0.41 & 0.17 \\
\hline 12 & 6 & 62.379 & 0.26 & 0.11 & 0.29 & 0.12 \\
\hline 13 & 6 & 62.945 & 0.23 & 0.12 & 0.26 & 0.11 \\
\hline 14 & 6 & 62.884 & 0.33 & 0.13 & 0.36 & 0.14 \\
\hline \multicolumn{2}{|c|}{$\overline{\bar{A}} / \mathrm{kBq} \mathrm{g}^{-1}$} & 62.743 & & & & \\
\hline \multicolumn{2}{|c|}{$S_{\mathrm{B}} / \%$} & 0.35 & & & & \\
\hline \multicolumn{2}{|c|}{$S_{\mathrm{W}} / \%$} & 0.12 & & & & \\
\hline \multicolumn{2}{|c|}{$S / \%$} & 0.37 & & & & \\
\hline
\end{tabular}


Table 7. Grand mean values $\bar{A}$ in units of $\mathrm{kBq} \mathrm{g}^{-1}$ for the massic activity of F2009 from efficiency tracing with SRM 4927F in 7 measurement trials. Each trial result was based on 5 replicate measurements of $A$ on each of 6 quench-varied sources. The great-grand mean $\overline{\bar{A}}$ was obtained from the average of the $7 \bar{A}$ values. Refer to text for definitions of the relative precision estimators, $s_{\mathrm{B}}, s_{\mathrm{W}}, s_{\mathrm{T}}, S_{\mathrm{B}}, S_{\mathrm{W}}$, and $S$.

\begin{tabular}{|c|c|c|c|c|c|c|}
\hline \multicolumn{2}{|c|}{ F2009 } & & & & & \\
\hline Trial & $n$ & $\bar{A} / \mathbf{k B q}^{-1}$ & $s_{\mathrm{B}} / \%$ & $s_{\mathrm{W}} / \%$ & $s_{\mathrm{T}} / \%$ & $\left(s_{\mathrm{T}} / \sqrt{ } \mathbf{n}\right) / \%$ \\
\hline 1 & 6 & 26.693 & 0.45 & 0.11 & 0.46 & 0.19 \\
\hline 2 & 6 & 26.716 & 0.36 & 0.11 & 0.38 & 0.16 \\
\hline 3 & 6 & 26.707 & 0.45 & 0.10 & 0.46 & 0.19 \\
\hline 11 & 6 & 26.575 & 0.54 & 0.20 & 0.57 & 0.23 \\
\hline 12 & 6 & 26.523 & 0.47 & 0.11 & 0.48 & 0.20 \\
\hline 13 & 6 & 26.730 & 0.13 & 0.09 & 0.16 & 0.06 \\
\hline 14 & 6 & 26.702 & 0.22 & 0.14 & 0.26 & 0.11 \\
\hline \multicolumn{2}{|c|}{$\overline{\bar{A}} / \mathrm{kBq} \mathrm{g}^{-1}$} & 26.664 & & & & \\
\hline \multicolumn{2}{|c|}{$S_{\mathrm{B}} / \%$} & 0.30 & & & & \\
\hline \multicolumn{2}{|c|}{$S_{\mathrm{W}} / \%$} & 0.17 & & & & \\
\hline \multicolumn{2}{|c|}{$S / \%$} & 0.35 & & & & \\
\hline
\end{tabular}


Table 8. Uncertainty assessment for the ${ }^{3} \mathrm{H}$ massic activity for SRM 4927G, where $u$ is a relative standard uncertainty for either a Type-A (evaluation by statistical methods) or Type-B (evaluation by other methods) assessment $[15,16]$.

\begin{tabular}{|c|c|c|c|}
\hline & Uncertainty component & Assessment & $u / \%$ \\
\hline 1 & $\begin{array}{l}\text { LS measurement precision; standard deviation of the great-grand mean } \\
\text { from } 14 \text { grand mean determinations, considering both between-mean } \\
(0.19 \%) \text { and typical within-mean }(0.12 \%) \text { variations. Each grand } \\
\text { mean is based on } 5 \text { or } 6 \text { sources and } 5 \text { replicate measurements The } \\
\text { within-mean variation on each of the } 14 \text { grand means includes the } \\
\text { between variation across the } 5 \text { or } 6 \text { sources (typically } 0.12 \% \text { ) and the } \\
\text { within variation for } 5 \text { measurements on each source (typically in the } \\
\text { range of } 0.2 \% \text { to } 0.4 \%) \text {. See Table } 4 \text {. }\end{array}$ & A & 0.23 \\
\hline 2 & $\begin{array}{l}\text { Background; LS measurement variability and cocktail composition } \\
\text { stability effect; wholly embodied in component } 1\end{array}$ & A & --- \\
\hline 3 & $\begin{array}{l}\text { Quench indicating parameter measurements; wholly embodied in } \\
\text { component } 1\end{array}$ & A & --- \\
\hline 4 & $\begin{array}{l}\text { Certified massic activity of SRM 4927F (1998 calibration by gas } \\
\text { counting) }\end{array}$ & B & 0.36 \\
\hline 5 & $\begin{array}{l}\text { Decay correction of SRM } 4927 \mathrm{~F} \text { to reference time for }{ }^{3} \mathrm{H} \text { half-life } \\
\text { uncertainty of } 0.20 \%\end{array}$ & $\mathrm{~B}$ & 0.19 \\
\hline 6 & Gravimetric dilution of SRM 4927F & B & 0.07 \\
\hline 7 & $\begin{array}{l}\text { Fitting of quench curves }\left({ }^{3} \mathrm{H} \text { efficiency versus quench indicating }\right. \\
\text { parameter), includes precision partially embodied in component } 1\end{array}$ & A & 0.08 \\
\hline 8 & Gravimetric dilutions of 3 sampled ampoules of SRM $4927 \mathrm{G}$ & $\mathrm{B}$ & 0.04 \\
\hline 9 & $\begin{array}{l}\text { Counting source aliquot mass determinations, includes mass } \\
\text { measurement precision partially embodied in component } 1\end{array}$ & $\mathrm{~B}$ & 0.05 \\
\hline 10 & $\begin{array}{l}\text { Decay correction of counting sources for }{ }^{3} \mathrm{H} \text { half-life uncertainty of } \\
0.20 \%\end{array}$ & B & 0.006 \\
\hline \multicolumn{3}{|c|}{ Relative combined standard uncertainty } & 0.48 \\
\hline \multicolumn{3}{|c|}{ Relative expanded uncertainty $(k=2)$} & 0.96 \\
\hline
\end{tabular}


Table 9. Comparison of the reported massic activities for the tritiated-water standards with decay to the comparison reference time, $t_{0}$, of 1200 EST, 1 May 2015 to the measured massic activities as traced with SRM 4927F.

\begin{tabular}{|l|c|c|c|c|c|}
\hline & \multicolumn{2}{|c|}{$\begin{array}{c}\text { Reported Massic Activity } A_{0} \text { at } \\
t_{0} \text { and the relative standard } \\
\text { uncertainties, } S^{\mathrm{a}}\end{array}$} & \multicolumn{2}{c|}{$\begin{array}{c}\text { Measured Massic Activity } \\
\overline{\bar{A}} \text { at } t_{0} \text { and relative } \\
\text { standard uncertainties } S_{\mathrm{T}}\end{array}$} & $\begin{array}{c}\text { Relative } \\
\text { Difference }\end{array}$ \\
\hline & $A_{0} /(\mathrm{kBq} / \mathrm{g})$ & $S / \%$ & $\overline{\bar{A}} /(\mathrm{kBq} / \mathrm{g})$ & $S_{\mathrm{T}} / \%$ & $\Delta / \%$ \\
\hline $4927 \mathrm{G}$ & - & - & 544.2 & 0.24 & - \\
\hline $4926 \mathrm{E}$ & 1.972 & 0.41 & 1.9737 & 0.2 & -0.09 \\
\hline F1994 & 63.4 & 0.57 & 62.743 & 0.37 & +1.05 \\
\hline F2009 & 26.25 & 0.6 & 26.664 & 0.35 & -1.58 \\
\hline KCRV & 26.594 & 0.48 & & & -0.26 \\
\hline
\end{tabular}

${ }^{\text {a }}$ Refer to Table 1.

${ }^{\mathrm{b}}$ Refer to Tables 4, 5, 6, and 7 . 
Table A1. Uncertainty assessment for the ${ }^{3} \mathrm{H}$ massic activity for SRM 4927F, SRM 4927G, and their ratio as determined by TDCR counting, where $u$ is a relative standard uncertainty for either a Type-A (evaluation by statistical methods) or Type-B (evaluation by other methods) assessment $[15,16]$.

\begin{tabular}{|c|c|c|c|c|}
\hline \multicolumn{2}{|c|}{$\begin{array}{l}\text { Uncertainty component } \\
\text { (Assessment type) }\end{array}$} & $\begin{array}{l}4927 \mathrm{~F} \\
u / \%\end{array}$ & $\begin{array}{l}4927 \mathrm{G} \\
u / \%\end{array}$ & $\begin{array}{l}\text { Ratio } \\
u / \%\end{array}$ \\
\hline 1 & $\begin{array}{l}\text { Standard deviation on the grand mean of } 6 \text { mean determinations } \\
\text { for } 6 \text { sources at } 3 \text { different levels of efficiency quenching ( } 2 \\
\text { each), considering both between-mean and the typical within- } \\
\text { mean variations. The mean for each source was based on } 3 \\
\text { replicate measurements on } 3 \text { separate measurement occasions. } \\
\text { The relative standard deviation for the between-mean }(n=6 \text { ) } \\
\text { variation is } 0.11 \% \text { and } 0.27 \% \text { for SRM } 4927 \mathrm{~F} \text { and } 4927 \mathrm{G} \text {, } \\
\text { respectively. The average relative standard deviation of the } \\
\text { mean for the typical within-mean variations is } 0.11 \% \text { and } 0.19 \% \\
\text { (SRM } 4927 \mathrm{~F} \text { and } 4927 \mathrm{G} \text {, respectively) as obtained from the } \\
\text { between-measurement occasion variability (typically both a } \\
\text { nominal } 0.1 \% \text { ) for each of the } n=6 \text { source means. (A) }\end{array}$ & 0.15 & 0.33 & 0.37 \\
\hline 2 & Gravimetric dilutions of SRM 4927F and SRM 4927G (B) & 0.04 & 0.04 & 0.06 \\
\hline 3 & $\begin{array}{l}\text { Counting source aliquant mass determinations, includes mass } \\
\text { measurement precision partially embodied in component } 1 \text { (B) }\end{array}$ & 0.05 & 0.05 & 0.07 \\
\hline 4 & $\begin{array}{l}\text { Background; estimated by propagating the standard deviation of } \\
\text { the mean on } 75 \text { background determinations. (A) }\end{array}$ & $2 \times 10^{-5}$ & $4 \times 10^{-5}$ & $6 \times 10^{-5}$ \\
\hline 5 & $\begin{array}{l}\text { Quenching model / } k B \text {; estimated as the standard deviation on } \\
\text { the recovered massic activity (or ratio) with efficiency curves } \\
\text { calculated by MICELLE2 using } 8 \text { different values for } k B \\
\text { ranging from } 0.005 \mathrm{~cm} \mathrm{MeV}^{-1} \text { to } 0.009 \mathrm{~cm} \mathrm{MeV}^{-1} \text { (B) }\end{array}$ & 1.3 & 1.3 & 0.006 \\
\hline 6 & $\begin{array}{l}\text { Model fit; estimated as the standard error of the fit of the } \\
\text { MICELLE2 data to a second-order polynomial function } \\
\text { (A) }\end{array}$ & $2 \times 10^{-5}$ & $2 \times 10^{-5}$ & $3 \times 10^{-5}$ \\
\hline 7 & $\begin{array}{l}\text { Decay correction of counting sources for }{ }^{3} \mathrm{H} \text { half-life uncertainty } \\
\text { of } 0.20 \% \text { (B) }\end{array}$ & 0.002 & 0.002 & $2 \times 10^{-5}$ \\
\hline 8 & $\begin{array}{l}E_{\beta \max } ; \text { uncertainty due to the uncertainty on the }{ }^{3} \mathrm{H} \text { beta endpoint } \\
\text { energy }(18.591(1) \mathrm{keV})(\mathrm{B})\end{array}$ & $2 \times 10^{-4}$ & $2 \times 10^{-4}$ & $2 \times 10^{-5}$ \\
\hline \multicolumn{2}{|c|}{ Relative combined standard uncertainty } & 1.31 & 1.34 & 0.38 \\
\hline \multicolumn{2}{|c|}{ Relative expanded uncertainty $(k=2)$} & 2.6 & 2.7 & 0.76 \\
\hline
\end{tabular}




\section{Figure Captions}

\section{Figure 1.}

General scheme used for the preparation and calibration of SRM 4927G, including use of quench-varied counting sources for comparative LS measurements against four other tritiated-water standards. Refer to text and Table 3 for additional detail.

\section{Figure 2.}

Counting scheme for the 14 comparison measurement trials showing the counter used for the measurements, the LS counting source series (Table 3), the midpoint time $T$ of the measurement trial in 2015 Julian Day Number (EST), half the total measurement length $\Delta T$ for the trial in days, and the tritium solutions (Table 1) compared in the trial with the number of counting sources.

\section{Figure 3.}

Typical ${ }^{3} \mathrm{H}$ spectra obtained with the Beckman LS counter, called "B", in terms of the backgroundsubtracted counting rate per channel $R_{\mathrm{c}}$ in units of counts per second per channel as a function of channel number $C \#$. The abscissa is a linear energy scale. The solid and dashed lines are for the most quenched and least quenched sources in a typical set (refer to Table 3), respectively. The upper discriminator level for the ${ }^{3} \mathrm{H}$ window was conservatively set at channel 50 for all comparison trials.

\section{Figure 4.}

Typical ${ }^{3} \mathrm{H}$ spectra obtained with the Wallac LS counter, called "W", in terms of the backgroundsubtracted counting rate per channel $R_{\mathrm{c}}$ in units of counts per second per channel as a function of channel number $C \#$. The abscissa is a logarithmic energy scale. The solid and dashed lines are for the most quenched and least quenched sources in a typical set (refer to Table 3), respectively. The upper discriminator level for the ${ }^{3} \mathrm{H}$ window was set at channel 400 for all comparison trials.

\section{Figure 5.}

Typical quench curve in terms of the ${ }^{3} \mathrm{H}$ efficiency $\varepsilon_{3}$ as a function of the quench indicating parameter $H \#$ for the Beckman counter B as developed with standard sources from SRM 4927F (open diamonds). The closed circles represent the traced efficiencies for sources of SRM 4927G at their measured values of $H \#$.

\section{Figure 6.}


Typical quench curve in terms of the ${ }^{3} \mathrm{H}$ efficiency $\varepsilon_{3}$ as a function of the quench indicating parameter SQPE for the Wallac counter W as developed with standard sources from SRM 4927F (open diamonds). The closed circles represent the traced efficiencies for sources of SRM 4927G at their measured values of $S Q P E$.

\section{Figure 7.}

The 14 grand mean values $\bar{A}$ in units of $\mathrm{kBq} \mathrm{g}^{-1}$ for the massic activity of SRM $4927 \mathrm{G}$ as represented in a three-part Fitzgerald plot that overlays the probability correlation coefficient (PPCC) graph and a frequency histogram of the same data. A normal $N(544.20,1.05)$ is superimposed on the histogram. The horizontal uncertainty bar on each datum correspond to the standard deviation of the mean $\left(s_{\mathrm{T}}, \sqrt{ } n\right)$ as given in Table 4. The left side ordinate $M$ is the Normal Order Statistic Median and the right-side ordinate is the frequency $f$. 


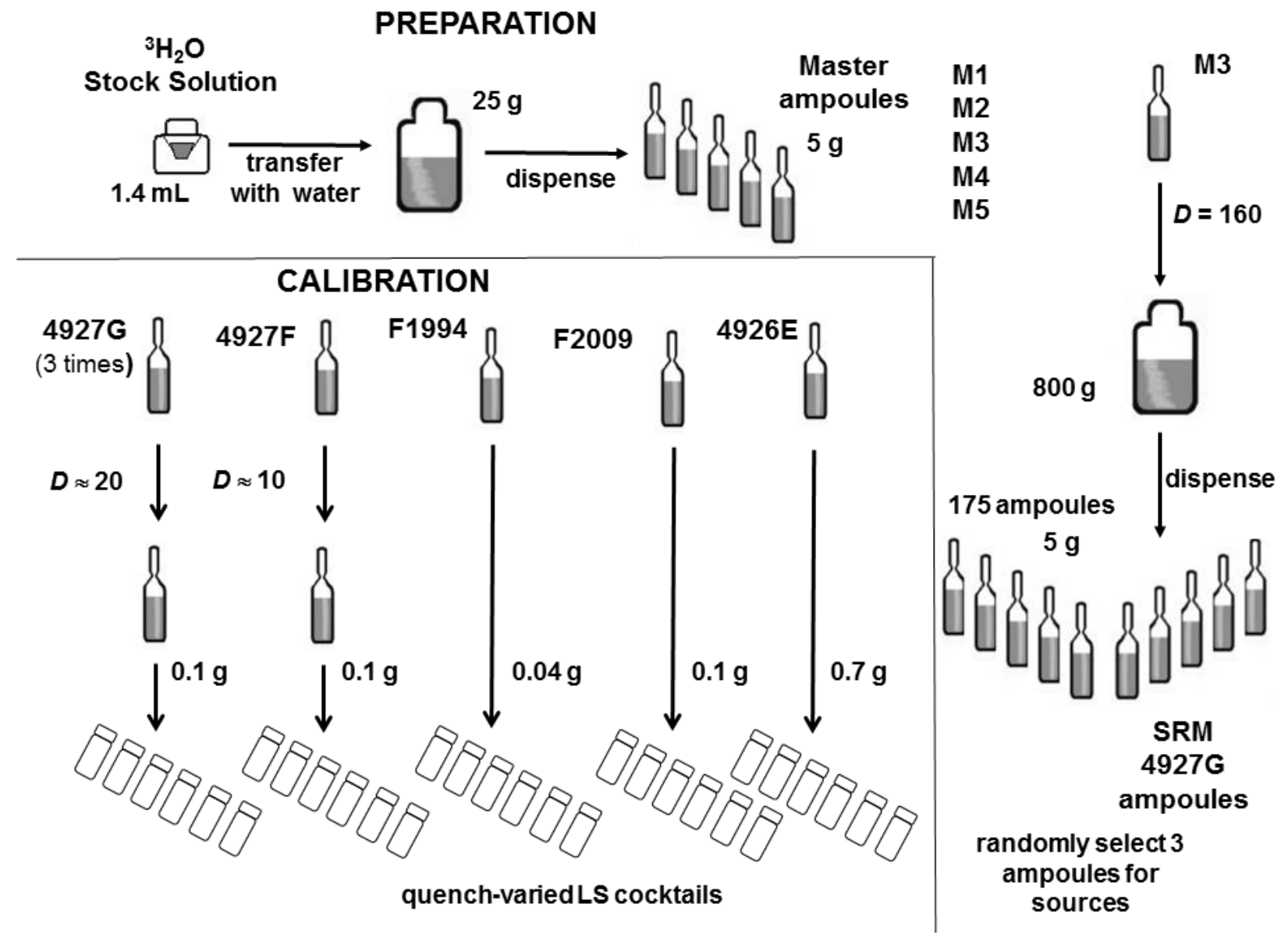

Figure 1 


\begin{tabular}{|c|c|c|c|c|c|c|c|c|c|}
\hline Trial & Counter & Series & $T / \mathrm{d}$ & $\Delta T / \mathrm{d}$ & $4927 \mathrm{~F}$ & $4927 \mathrm{G}$ & $4926 \mathrm{E}$ & F2009 & F1994 \\
\hline 1 & B & I & 112.45 & 0.82 & 6 & 5 & & 6 & \\
\hline 2 & W & I & 114.27 & 0.80 & 6 & 5 & & 6 & \\
\hline 3 & B & I & 118.42 & 0.81 & 6 & 5 & & 6 & \\
\hline 4 & B & II & 121.42 & 0.82 & 6 & 5 & & & 6 \\
\hline 5 & W & II & 128.32 & 0.80 & 6 & 5 & & & 6 \\
\hline 6 & B & II & 132.44 & 0.82 & 6 & 5 & & & 6 \\
\hline 7 & W & III & 150.40 & 0.82 & 6 & 6 & 6 & & \\
\hline 8 & B & III & 154.26 & 0.83 & 6 & 6 & 6 & & \\
\hline 9 & W & III & 160.23 & 0.81 & 6 & 6 & 6 & & \\
\hline 10 & W & III & 162.30 & 0.81 & 6 & 6 & 6 & & \\
\hline 11 & B & IV & 168.69 & 1.07 & 6 & 6 & & 6 & 6 \\
\hline 12 & W & IV & 175.59 & 1.05 & 6 & 6 & & 6 & 6 \\
\hline 13 & W & VI & 189.62 & 1.05 & 6 & 6 & & 6 & 6 \\
\hline 14 & B & VI & 192.47 & 1.05 & 6 & 6 & & 6 & 6 \\
\hline
\end{tabular}

Figure 2 

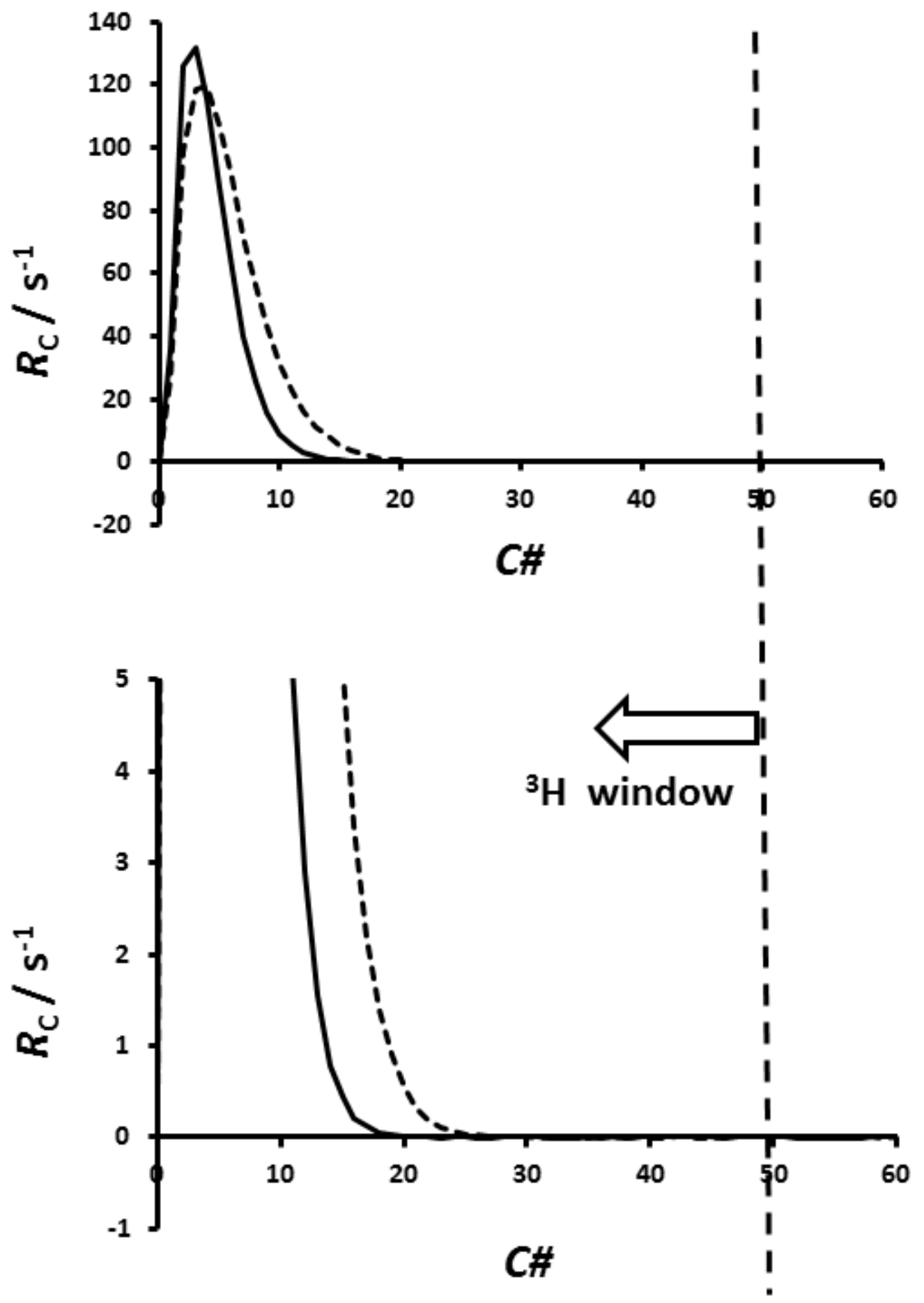

Figure 3 

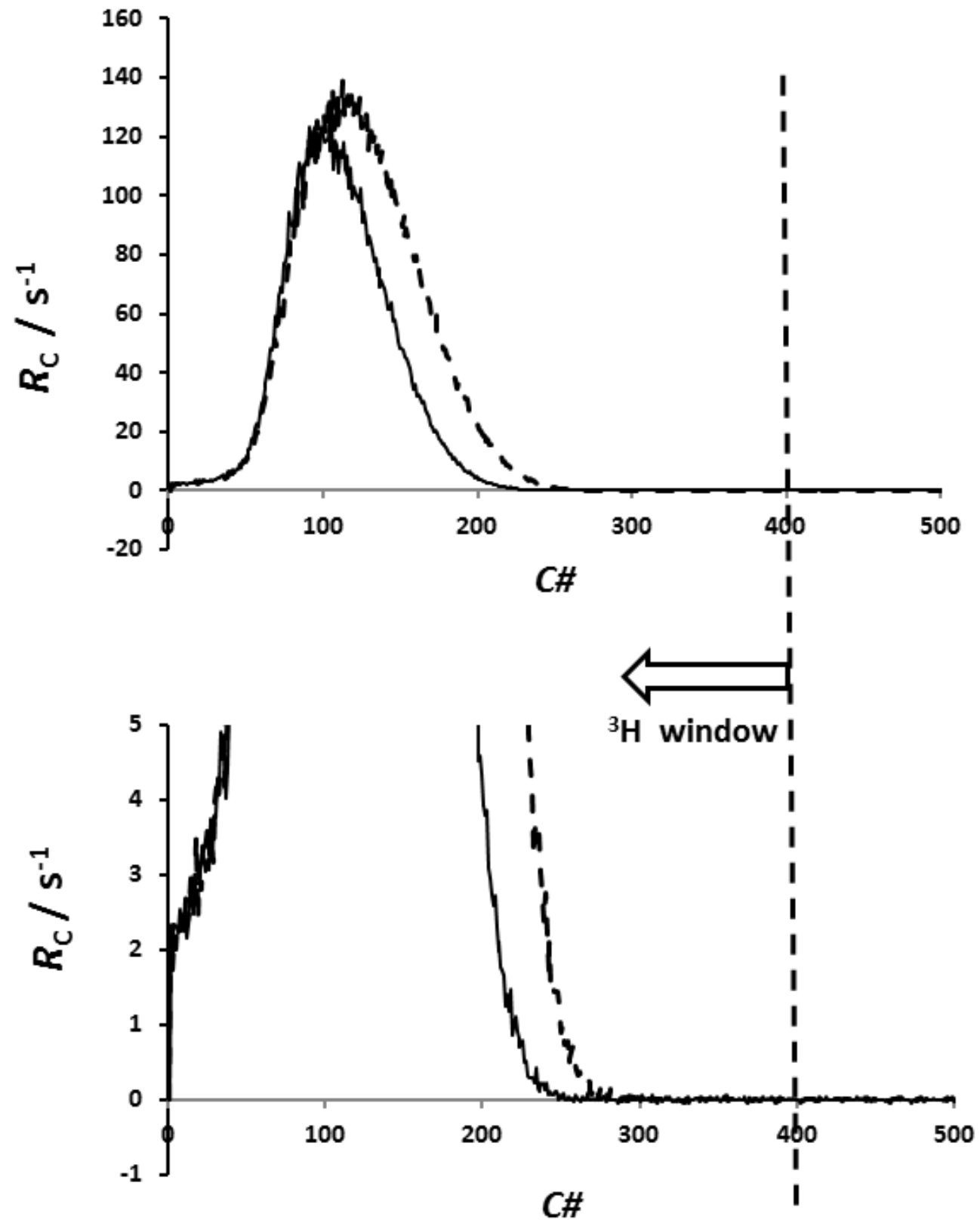

Figure 4 


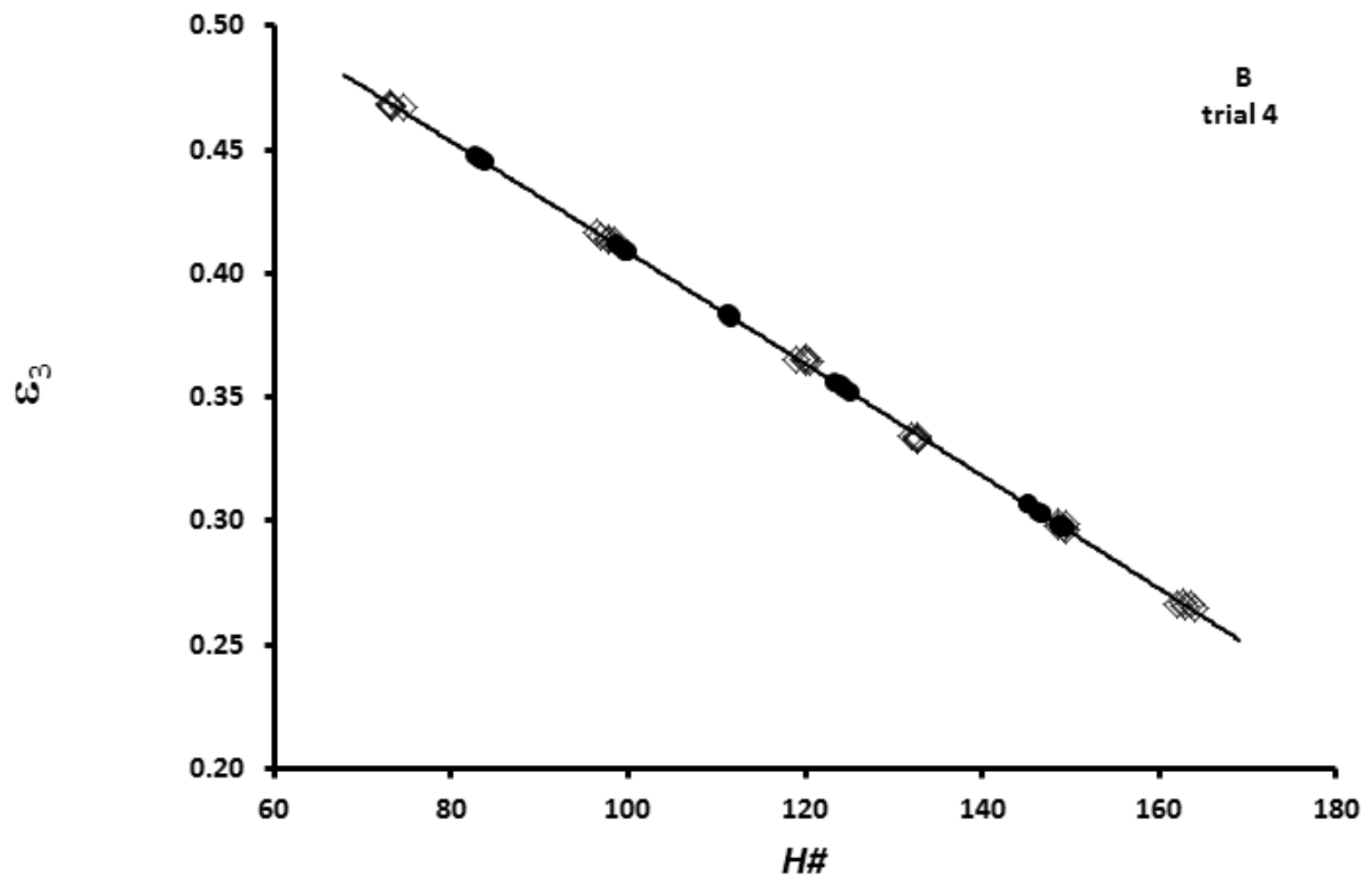

Figure 5 


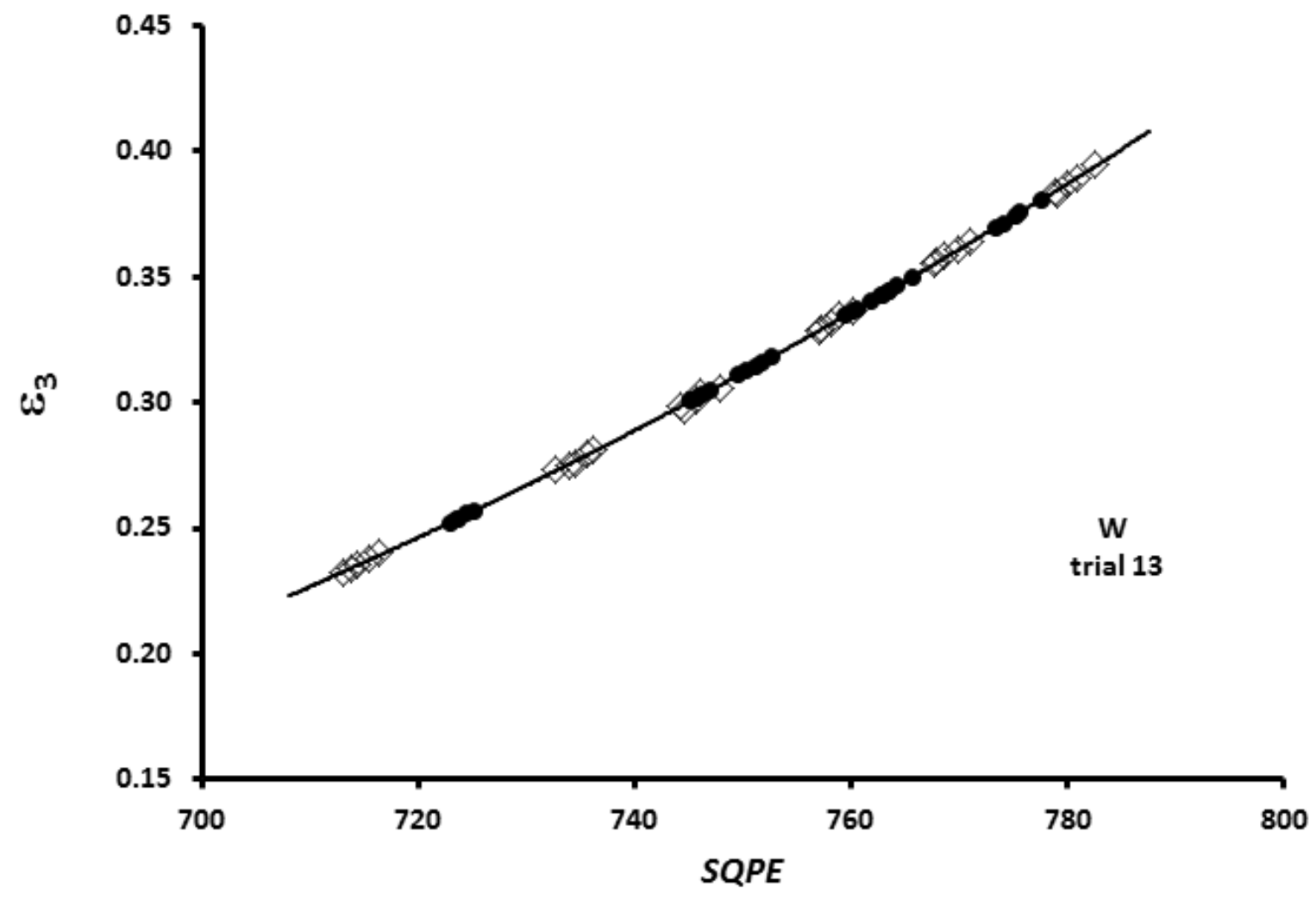

Figure 6 


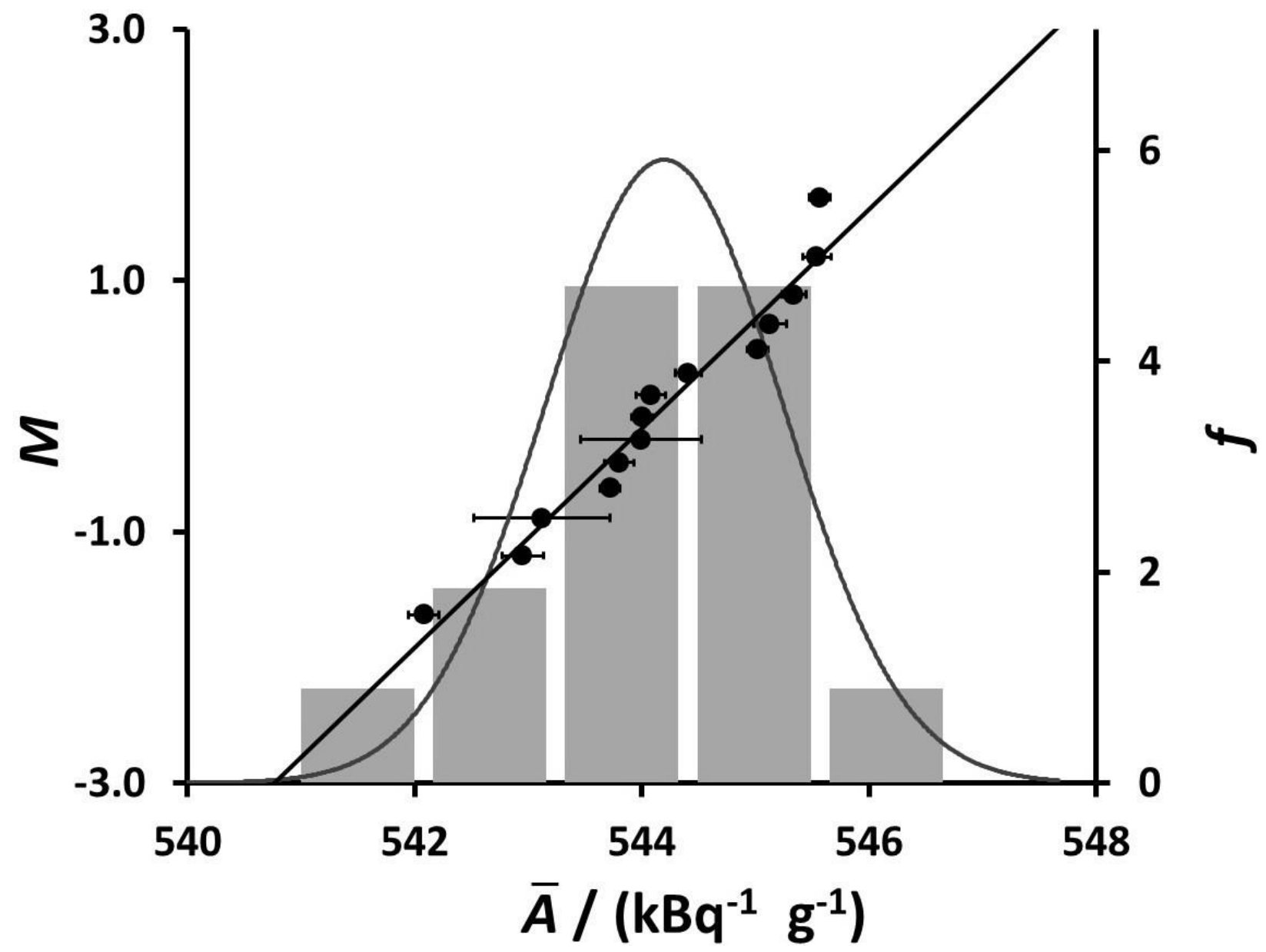

Figure 7 